University of Nebraska - Lincoln

DigitalCommons@University of Nebraska - Lincoln

Publications, Agencies and Staff of the U.S.

Department of Commerce

U.S. Department of Commerce

2019

Bore-ing into Nocturnal Convection

Kevin R. Haghi

Bart Geerts

Hristo G. Chipilski

Aaron Johnson

Samuel Degelia

See next page for additional authors

Follow this and additional works at: https://digitalcommons.unl.edu/usdeptcommercepub

This Article is brought to you for free and open access by the U.S. Department of Commerce at DigitalCommons@University of Nebraska - Lincoln. It has been accepted for inclusion in Publications, Agencies and Staff of the U.S. Department of Commerce by an authorized administrator of DigitalCommons@University of Nebraska - Lincoln. 


\section{Authors}

Kevin R. Haghi, Bart Geerts, Hristo G. Chipilski, Aaron Johnson, Samuel Degelia, David Imy, David B.

Parsons, Rebecca D. Adams-Selin, David D. Turner, and Xuguang Wang 


\section{Bore-ing into Nocturnal Convection}

Kevin R. Haghi,

University of Washington, Seattle, Washington

Bart Geerts,

University of Wyoming, Laramie, Wyoming

Hristo G. Chipilski, Aaron Johnson, and Samuel Degelia, University of Oklahoma, Norman, Oklahoma

David Imy,

Storm Prediction Center, Norman, Oklahoma

David B. Parsons,

University of Oklahoma, Norman, Oklahoma

Rebecca D. Adams-Selin, Atmospheric and Environmental Research, Inc., Offutt Air Force Base, Nebraska

David D. Turner, Global Systems Division, NOAA/OAR/ESRL, Boulder, Colorado

Xuguang Wang, University of Oklahoma, Norman, Oklahoma

\section{Abstract}

There has been a recent wave of attention given to atmospheric bores in order to understand how they evolve and initiate and maintain convection during the night. This surge is attributable to data collected during the 2015 Plains Elevated Convection at Night (PECAN) field campaign. A salient aspect of the PECAN project is its focus on using multiple observational platforms to better understand convective outflow boundaries that intrude into the stable boundary layer and induce the development of atmospheric bores. The intent of this article is threefold: 1) to educate the reader on current and future foci of bore research, 2) to present how PECAN observations will facilitate aforementioned research, and 3) to stimulate multidisciplinary collaborative efforts across other closely related fields in an effort to push the limitations of prediction of nocturnal convection. 


\title{
BORE-ING INTO NOCTURNAL CONVECTION
}

\author{
Kevin R. Haghi, Bart Geerts, Hristo G. Chipilski, Aaron Johnson, Samuel Degelia, David Imy, \\ David B. Parsons, Rebecca D. Adams-Selin, David D. Turner, and Xuguang Wang
}

This article presents a survey of atmospheric bores, their role in the initiation and

organization of deep convection, and a vision for improving the forecast of atmospheric

bores and nocturnal convection through a multidisciplinary approach.

0 $\mathrm{n}$ the afternoon of the 10 July 2015 in Hays, Kansas, during the Plains Elevated Convection at Night (PECAN) field campaign (Geerts et al. 2017), the bore group was selected to lead the evening's intensive observation period (IOP). The PECAN forecasters deemed the potential for bore development medium-to-high based on a theorybased algorithm that characterized the conditions necessary to develop and sustain a bore. The theoretical parameters of the algorithm were calculated

AFFILIATIONS: HAGHI-University of Washington, Seattle, Washington; GeERTS-University of Wyoming, Laramie, Wyoming; Chipilski, Johnson, Degelia, Parsons, and Wang-University of Oklahoma, Norman, Oklahoma; IMY-Storm Prediction Center, Norman, Oklahoma; Adams-SeLIN-Atmospheric and Environmental Research, Inc., Offutt Air Force Base, Nebraska; TURNERGlobal Systems Division, NOAA/OAR/ESRL, Boulder, Colorado CORRESPONDING AUTHOR: Kevin R. Haghi, kevin.haghi@gmail.com

This article is part of the PECAN special collection.

The abstract for this article can be found in this issue, following the table of contents.

DOI:I0.II75/BAMS-D-17-0250.I

In final form 17 October 2018

(C)2019 American Meteorological Society

For information regarding reuse of this content and general copyright

information, consult the AMS Copyright Policy. from data produced in multiple convection-allowing models, including experimental ones.

Urgently, the bore lead scientist disseminated the travel plans for the mobile PECAN Integrated Sounding Arrays (mPISAs), the mobile sounding vehicles, and the mobile radar trucks through program communication channels. The resulting carefully placed network of instruments (deemed "the glove" for its visual resemblance) were positioned to capture transects along multiple segments of the same bore, one objective of the bore group. Aircraft transects were made by several platforms: the National Aeronautics and Space Administration (NASA) DC-8 aircraft carrying a downward pointing NASA Langley Lidar Atmospheric Sensing Experiment differential absorption lidar (LASE DIAL) (Browell et al. 1997), designed to measure water vapor and aerosols along their flight transects, and the Wyoming King Air with a compact Raman lidar. Time-height sections from the ground-based upward pointing profilers captured horizontal/vertical motion, moisture, and temperature. Pre- and postbore environments were sampled with atmospheric soundings and the Kansas Mesonet recorded changes in temperature, pressure, and winds.

It required a lot of planning and a little luck, but the 10-11 July 2015 IOP and other successful deployments during PECAN provided scientists with an unprecendented new set of data needed to establish 
how well do our current theoretical predictions reproduce the observed dynamic and thermodynamic structure of atmospheric bores. For example, cross sections through the 11 July bore provide evidence that large vertical displacements can occur above the theorized bore height (Fig. 1), as previously documented by Koch et al. (2008a). Additionally, multiple cross sections along the length of the same bore confirm that remarkably different structures and modes can be forced by the same convective cold pool (Fig. 2). As illustrated in Fig. 2, the variability along the bore was something that was anticipated, but never before measured.

In the face of such heterogeneity and complexity, we ask: What can theory's few tractable solutions offer? Can numerical models fill the gap, and are they subject to their own mathematical and numerical uncertainties? Prior to the International $\mathrm{H}_{2} \mathrm{O}$ Project (IHOP_2002; Weckwerth and Parsons 2006) and now PECAN, these questions were difficult to posit because so little was known about how and when bores assist in the generation and maintenance of convection. The intent of this article is to bring needed attention to bores by familiarizing readers with 1) the future focus of bore research, 2) how PECAN observations are currently being utilized to supplement the bore research, and 3) ongoing and future multidisciplinary collaborative efforts including in allied basic sciences. As a result, the effort should push back the limitations of prediction of nocturnal convection.

Understanding the role of bores in nocturnal convection over the Great Plains is strongly in the public's interest since nocturnal convective systems, in particular mesoscale convective systems (MCSs), account for up to $70 \%$ of the warm season precipitation in the Great Plains (Fritsch et al. 1986). Additionally, MCSs frequently create damaging straight-line winds and hail. An MCS can emerge under weakly forced synoptic conditions (Trier et al. 2010), making their evolution and predictability more sensitive to mesoscale phenomena, such as a bore. Therefore, improving our representation of bores should improve weather and even climate models, including for instance their resolution of the climatological nocturnal precipitation maximum-a phenomenon that is poorly simulated not only in models with parameterized convection (Davis et al. 2003; Fritsch and Carbone 2004; Clark et al. 2007; Gustafson et al. 2014), but also in models that permit convection (Gao et al. 2017; Feng et al. 2018).

To get a sense of why atmospheric bores have only recently received more attention, it is important to recognize that bores were first identified over water as tidal bores. One of the earliest records of a tidal bore occurred in water and dates back to the eleventh century on the Qiantang River in China. Tidal bores commonly form on this river when a cooler incoming ocean tide undercuts warmer river water at the river's estuary. The inability of the warmer freshwater to completely override the cooler and salty upstreamsurging ocean water results in a bore that moves upstream, at times reaching several meters of height. ${ }^{1}$ Similar tidal bores have been observed in numerous estuaries over the globe.

It took until the twentieth century before bores were recognized to also exist in the atmosphere. A convectively induced bore was not identified until the night of 16-17 May 1948 in Ohio (Tepper 1950) during the Thunderstorm Project. A network of 50 surface stations with a typical spacing of $3 \mathrm{~km}$ was placed in a rectangular area. Station pressure,

${ }^{1}$ Chinese lore refers to this crashing bore along the shore as the Silver Dragon.

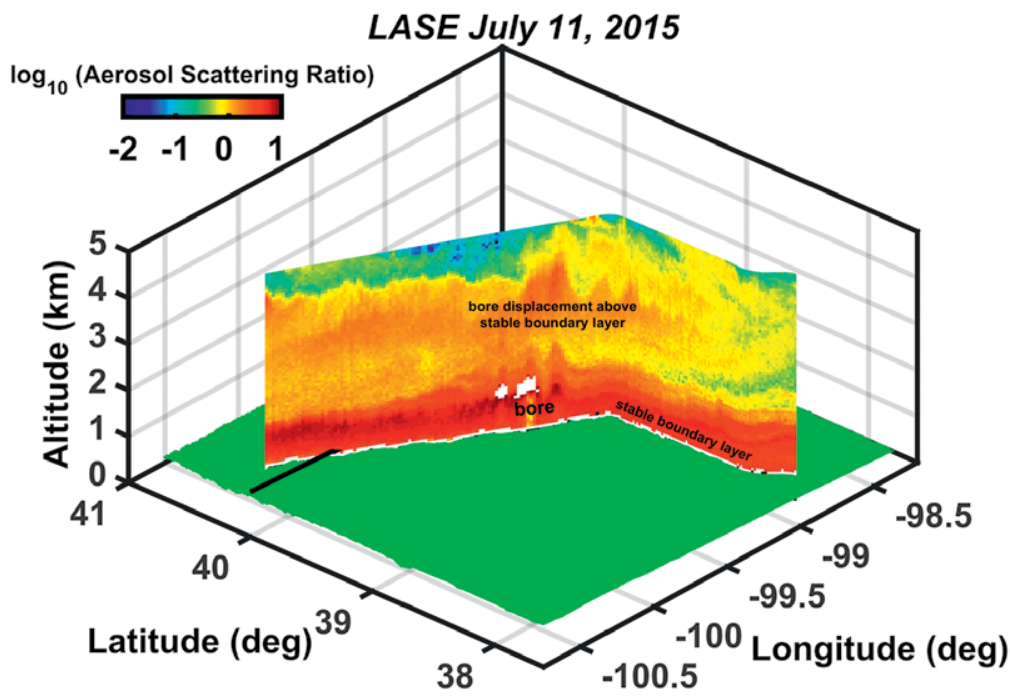

FIG. I. Time-height cross section through the II Jul bore of aerosol scattering ratios measured by LASE from the NASA DC-8 aircraft. Changes in the height of the aerosol layers as the DC-8 transects the bore can be loosely interpreted as proxies for layer lifting. The highest concentrations of aerosols near the surface are confined to the stable boundary layer. 
temperature, and wind signatures identified a wave disturbance leading the arrival of an MCS. It was not until half a century later that the interaction between bores and deep convection was studied again (Carbone et al. 1990; Karyampudi et al. 1995; Koch and Clark 1999). The first field project to directly address bores was IHOP_2002, whose data provided evidence that bores commonly develop along the outflow of an MCS, and may initiate convection (Wilson and Roberts 2006; Haghi et al. 2017; Parsons et al. 2018). Other studies have identified the generation of an atmospheric bore, but not as a result of convective outflows. Instead, these studies identified the impetus of bore development as frontal boundaries extending over the English Channel (Pothecary 1954), or katabatic flows over the Gulf of Carpentaria in northern Australia (called "morning glory"; Clarke 1972; Fig. 3c). Some other examples are provided in Fig. 3.

Past studies on organized convection captured two subtle but powerful feedbacks of bores on convective initiation and maintenance. First, idealized studies (Parker 2008; French and Parker 2010) and real-time (Blake et al. 2017) numerical simulations of squall lines have shown that a bore propagating through the stable boundary layer (SBL) is capable of lifting unstable air, leading to the development of deep convective cells that merge into an MCS. In this
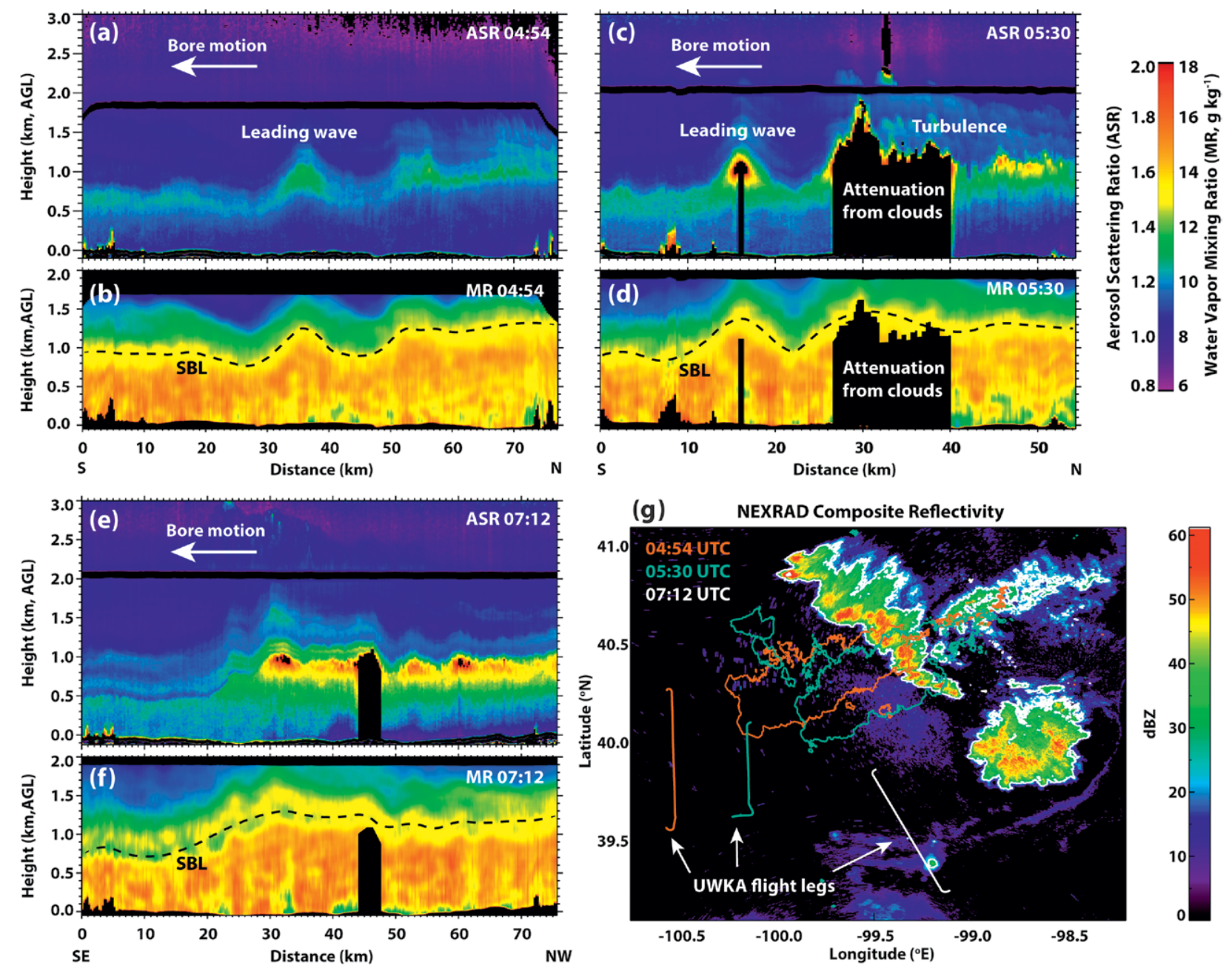

Fig. 2. (a)-(f) Vertical transects through the II Jul bore of aerosol scattering ratio (ASR) and water vapor mixing ratio from the lidars aboard the Wyoming King Air at three different times for the same II Jul bore as in Fig. I. ASR is sampled above and below the aircraft, mixing ratio below flight level only. (g) Map of radar reflectivity at the time of the third transect, showing the three transect locations (flight tracks) and schematic location of the MCS at the two earlier times. Variability between transects likely is attributable to changes in the environmental structure and evolution of the bore: the earliest transect exhibits a small wave, the next one exhibits a higher-amplitude wave and more turbulence behind the initial wave, and the last transect reveals a highly turbulent bore with no distinct leading wave. 
way, a bore can sustain an MCS. Second, bore lifting was sufficient to trigger pristine convection by lifting layers (usually from the upper SBL or even higher) to their level of free convection (LFC) or by reducing convective inhibition (CIN) sufficiently for a density current to trigger convection (Koch et al. 1991; Koch and Clark 1999). These mechanisms have received little study until recently.

The 2015 PECAN field campaign was designed to study multiple aspects of an MCS and its environment, including the low-level jet (LLJ), the SBL, convection initiation (CI), the microphysics and dynamics of an MCS, and atmospheric bores. PECAN took place from 1 June to 15 July 2015 with an observing strategy that included a large array of profiling systems and scanning radars, many mobile, in order to target MCSs over a large domain covering the Great Plains. The instruments on the mobile and fixed PISAs included a combination of surface in situ sensors, radiosondes, and passive and active profiling systems, and provided continuous profiles of wind, temperature, humidity, and aerosol layers, at sufficient resolution to dissect bores (Geerts et al. 2017). In total, six IOPs and two unofficial field operations were dedicated to bores, and bores were sampled during several other IOPs that focused on MCS and CI processes.

The following are the four bore-centric objectives that guided the PECAN experimental design:

1) Determine the environmental controls over initiation, structure, propagation, and evolution of bores, solitons, and other trapped wave disturbances.

2) Collect data on the initiation and maintenance of convection as a result of wavelike SBL disturbances.

3) Determine when bores pull away from or remain an integral part of a density current.

4) Improve bore representation in the convectionallowing models.

ATMOSPHERIC BORES: A PRIMER. Before discussing the current state of bore research, a bit of background is in order: What is an atmospheric

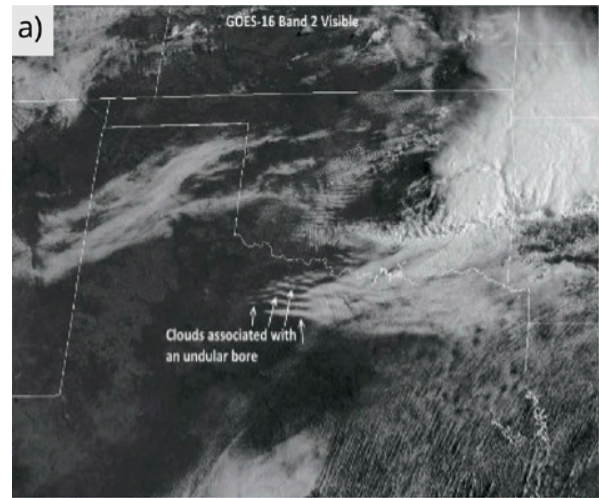

b)

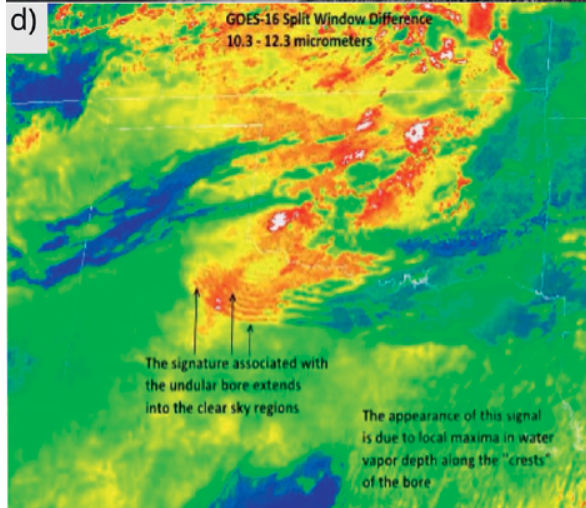

d
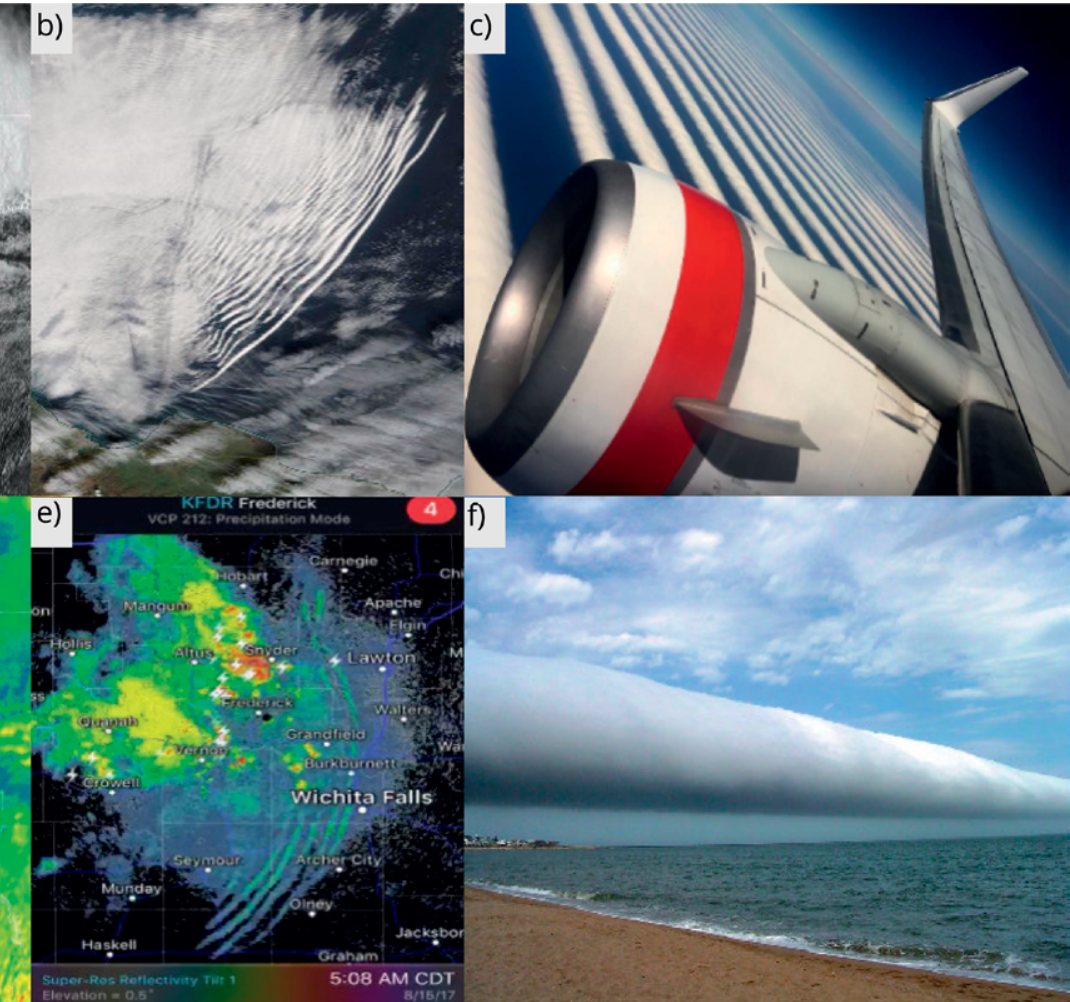

FIG. 3. (a) Visible satellite imagery from GOES-I6 of an undular bore over Texas with undulations identified (courtesy of NOAA). (b) As in (a), but for a bore over the Gulf Coast. (c) "Morning Glory" seen from Virgin Australia flight (courtesy of Virgin Australia, @VirginAustralia). (d) GOES-I6 water vapor channel (courtesy of NOAA). (e) Radar reflectivity images of an undular bore over Oklahoma, (courtesy of Noah Brauer, @NOAABrauer). (f) Images of a bore developed from a sea/land breeze interaction (courtesy of @Weatherology Twitter account). Disclaimer: data from GOES-16 data are preliminary. 
bore? It is best to start with the atmospheric analog in water, the hydraulic jump, which the AMS Glossary of Meteorology defines as a "sudden and usually turbulent passage of water in an open channel from low stage, below critical depth, to high stage, above critical depth." In the case of the atmosphere, the water is replaced by a stably stratified fluid of air adjacent to the ground. In the AMS definition, "critical" is defined by whether waves can propagate upstream, or if the flow is faster than all wave speeds. The more atmospheric relevant internal wave can arise in a stratified flow when a light fluid, resting underneath a reference atmosphere of remarkably larger depth, is intruded by a dense fluid or a solid obstruction. When the lighter fluid is unable to completely surmount the denser fluid (or solid obstruction), is it possible to develop an internal bore. Hydraulic theory can be used to determine when blocking occurs. This theory hinges on two important parameters, the Froude number and the nondimensional height (Houghton and Kasahara 1968; Rottman and Simpson 1989; Baines 1995). ${ }^{2}$ The Froude number Fr is a ratio of the kinetic energy available in the lighter fluid divided by the potential energy required to surmount the denser fluid. The nondimensional height $H$ is a ratio of the depth of the light ground-adjacent fluid to the depth of the obstruction.

A typical physical process for the generation of a bore is depicted in Fig. 4 and described as follows. Consider a stably stratified fluid adjacent to the ground with a thickness $h_{0}$ (Fig. 4a). Such a stable layer commonly forms at night adjacent to the ground through radiative heat loss in a frictionless, nonrotating atmosphere. ${ }^{3}$ Any small distortion will, according to hydraulic theory (Baines 1995), separate into two parts that move upstream/downstream at a ground-relative speed $\pm C_{0}$ minus the speed of the downstream-moving background flow $U$ (Fig. 4a). When determining the criticality of the flow, consideration is given to a distortion moving upstream against the background flow. If $U>C_{0}$, the flow is considered supercritical; thus, gravity waves are traveling upstream slower than the incoming flow, and all disturbances are eventually swept downstream. Now consider a supercritical flow that encounters an obstruction with height $d_{0}$ (Fig. 4a). There is a loss of its horizontal kinetic energy within the supercritical flow as it is converted to potential energy in an attempt to surmount the aforementioned obstruction, thereby reducing the horizontal flow speed. The result of this exchange leads to a vertical expansion of the stable layer. When the retarding fluid speed is great

\footnotetext{
${ }^{2}$ For a schematic, see Rottman and Simpson (1989) and Haghi et al. (2017).

${ }^{3}$ Note that frictionless and nonrotating conditions are assumed to be valid for the development time scale of nearly all bores, even though direct observation of their effects on an atmospheric bore does not readily exist. For observed Great Plains weather scales, future studies should consider the effects of friction and Coriolis forces.

${ }^{4} C_{0}=\sqrt{g^{\prime} h_{0}}$ where $g^{\prime}$ is the reduced gravity.
} 
enough to render the flow subcritical in this upstream area, a bore will inevitably develop. The bore manifests as a sudden jump where the flow transitions from supercritical to subcritical (Rayleigh 1914), arriving at a height $h_{1}$ (Fig. 4). In the atmosphere, the "obstacle" and flow may be moving relative to a ground station, where the bore passage is recorded as a sustained pressure rise with either a lack or increase in the temperature at the surface. The temperature changes occur when warmer air along the top of the SBL is mixed down to the surface through circulations inside the subcritical portion of the bore.

Convectively generated cold pools (such as from an MCS) and other density currents (such as sea breezes or cold fronts) may develop bores when they intrude into a SBL of sufficient depth. The nocturnal southerly LLJ, common over the Great Plains in summer, often generates the northward-moving supercritical flow. The supercritical flow, as discussed, is a necessary condition for priming the development of an upstream-moving bore.

Internal gravity waves can arise in the subcritical regime of the bore as undulations that propagate at a phase speed according to its wavelength. Highfrequency gravity waves, such as those associated with an undular bore, that do not leak a significant amount of energy vertically and instead propagate horizontally for long distances are said to be "trapped" (Scorer 1949). While undular appears to encompass all cases of bores that appear wavy, such undulations can quickly amplify to where nonlinear wave steepening ${ }^{5}$ becomes important. If this nonlinear steepening balances the effects of dispersion, ${ }^{6}$ the gravity waves evolve into a train of amplitude-ordered solitary waves called a soliton (Fig. 4b). A solitary wave by definition moves at a speed faster than the critical flow speed (Christie 1989) and, as a result, move into the supercritical flow upstream of the transition between super- and subcritical flow (Fig. 4b). Because a solitary wave in the supercritical regime is ahead of the displacement of the SBL by the bore, parcels displaced by a solitary wave that do not saturate return to their original height. While a vertical profile of the winds would reveal the remarkably different structure of gravity wave undulations along a bore and solitary waves, they are difficult to distinguish using satellite or radar imagery alone (as in Fig. 3).

\section{FUTURE AVENUES OF RESEARCH. Early} results were shared at the first PECAN workshop, ${ }^{7}$ during the American Meteorological Society conference presentations, and in peer-reviewed articles. The following topics have been identified as the focus of future studies regarding the representation of bores and subsequent generation of convection.

Atmospheric-specific bore theory. Recall that the operations during PECAN analyzed the output from a theory-based algorithm that used NWP model data as input to predict whether a MCS would develop a bore. ${ }^{8}$ The algorithm was simple: determine if a density current will generate a bore and a suitable wave duct is in place (using the parameters Fr and $H$ from hydraulics and the Scorer parameter from linear wave theory). An assumption was then applied: the parameters in the algorithm also hold prognostic capabilities. The theory-based algorithm required the following parameters: $d_{0}, C_{\mathrm{dc}}, \Delta \theta$ (the inversion strength), and $h_{0}$ (Fig. 4). ${ }^{9}$

While the theory-based algorithm performs well for predicting the development of a bore, it was not designed to examine when will the onset of bore-initiated convection occur. Three internal factors that affect bore-initiated convection are the depth of the mechanical lifting due to the hydraulic jump, the amplitude of individual gravity waves within the subcritical regime, and the resonance period that a parcel will spend above their LFC. One limitation is addressed in an observational study by Toms et al. (2017) that indicates the application of hydraulic theory can overestimate the height and speed of a bore by as much as $15 \%$ [this range is also

\footnotetext{
${ }^{5}$ Wave steepening is the process where the deepest portions of the wave move faster than its surrounding fluid and steepens the profile of a wave toward its leading edge, much like what is observed when an ocean wave approaches a beach.

${ }^{6}$ Dispersion is the separation of waves in horizontal space due to the dependence of a wave's speed on its horizontal wavelength.

${ }^{7}$ For presentations given during the workshop, visit http://pecan.ou.edu/.

${ }^{8}$ The models utilized for the theory-based algorithm were the National Severe Storms Laboratory Weather Research and Forecasting (WRF) Model (NSSL-WRF), the University of Oklahoma Multiscale Assimilation and Predictability (MAP) 1-km deterministic WRF, and the operational version of the High Resolution Rapid Refresh Experimental Model (HRRR). The models were best suited for the theory-based algorithm because the higher horizontal and vertical resolution theoretically produces a better representation of the mesoscale outflows.

${ }^{9}$ See Rottman and Simpson (1989) and Haghi et al. (2017) for a full description of how these parameters are used in finding Fr and $H$.
} 
obtained by Johnson et al. (2018) using the University of Oklahoma Multi-scale Data Assimilation and Predictability Laboratory (OU MAP) 1-km deterministic model], which will inevitably impact the depth of the mechanical lifting and the resonance period. While $15 \%$ may be inconsequential in very convectively unstable/stable environments, there is an intermediate range of environments where the small error will impact the uncertainty of prognostic results. Additionally, hydraulic theory does not provide an estimate of the magnitude of the vertical motion within or above the bore because hydraulic theory patches the subcritical and supercritical flow together through introducing a nonaccelerating discontinuity at the jump. The discontinuity makes a mathematical depiction of the vertical motion in two-layer hydraulic theory impossible. Therefore, any attempt to calculate the vertical motion would be purely heuristic, and would give no information about the motion of air above the bore since hydraulic theory assumes a neutral reference layer atop the SBL.

To be more relevant, theoretical research should be focused on four key aspects that are inadequately handled with current theory (Fig. 5): the height and speed of a density current, the non-steady-state evolution of a bore, the impact of stability above the wave duct on weakly nonlinear wave solutions, and the interaction of bores with tropospheric gravity waves.

Theoretical descriptions of density currents are a challenge to generalize for the atmosphere (e.g., evolution of the density current shape and speed with time in a complicated environment). However, comparisons between numerical and simplified analytical models are useful tools to provide insight for improvements to a more atmospheric-specific analytical model (e.g., White and Helfrich 2012). As a measure of improvement, a new analytical model should include estimations of $d_{0}$ and $C_{\mathrm{dc}}$ in an atmosphere with varying stability and winds, since $d_{0}$ and $C_{\mathrm{dc}}$ are parameters that determine if a bore will form (Figs. 4 and 5). The two most current atmospheric theoretical models of density currents to date are valid under environmental conditions with shear (Bryan and Rotunno 2014) or varying stratification (White and Helfrich 2014) with energy dissipation taken into account. Yet, neither of these analytical models allows for jetlike profiles of wind within complex profiles of stability, common attributes of the Great Plains environment. Because an elegant analytical model for these conditions may not exist, analysis of numerical models may often need to supplement theory. Idealized sensitivity studies of density currents intruding into observed

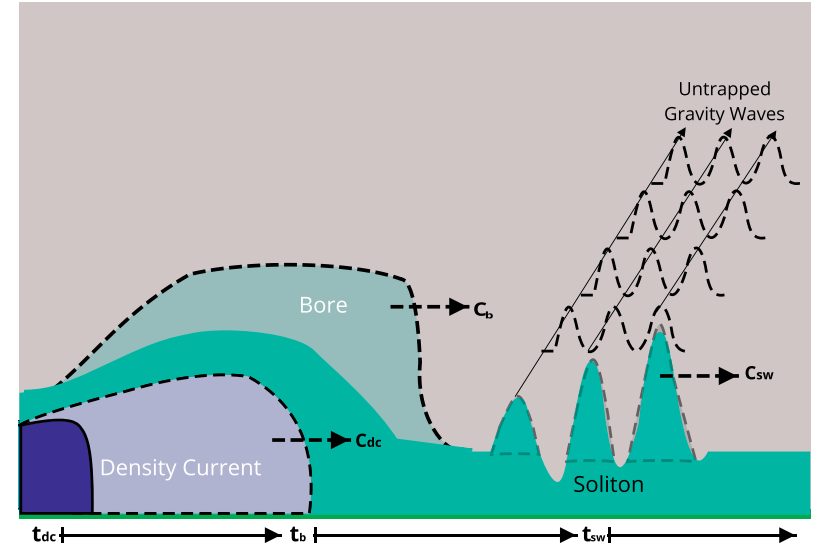

FIG. 5. An illustration of the uncertainty that exists in predicting the typical bore/soliton life cycle. The dotted lines identify areas of uncertainty in the speed and shape of a density current, the growth of the atmospheric bore, the soliton, and the upward propagating gravity waves above the wave duct. Time progresses from left to right, starting with the spreading of a density current, the development of the bore, and the evolution into a soliton.

environments during PECAN are underway using a numerical model (Cloud Model 1). ${ }^{10}$

Assuming that present theory on density currents can perfectly capture the shape and speed of a density current, the speed and shape are only valid if the density current is in a quasi-steady state, ignoring the evolution due to changing conditions (Fig. 4). Subsequently, because predictions based on bore theory are dependent on an accurate characterization of the density current, it is necessary to incorporate time-dependent solutions for a density current. Successful time-dependent density current theory will lead to proper evaluation of how changes to a bore ahead of an actively convective side of an MCS modulate the MCS's strength and propagation speed. Numerical solutions of bores in nocturnal environments, such as those of French and Parker (2010) and Blake et al. (2017), will be crucial to developing a corresponding unsteady bore state solution.

Results using variations of weakly nonlinear theories-such as Korteweg-deVries (KdV; Miles 1980), Benjamin-Davies-Ono (BDO; Christie 1989), and Dubreil-Jacotin-Long (DJL; White and Helfrich 2014) - depict a more complete, yet idealized account of the evolution from a bore to a packet of solitary waves. Solutions to KdV and BDO exist for environments that possess varying stratification within a wave duct [using KdV (Lamb and Yan 1996)

\footnotetext{
${ }^{10}$ Cloud Model 1 is available for download at www2.mmm .ucar.edu/people/bryan/cml/.
} 
or DJL (White and Helfrich 2012)] and with linearly varying shear included [using $\mathrm{KdV}$ and $\mathrm{BDO}$ (Rottman and Einaudi 1993) or DJL (Stastna and Lamb 2002)], but with a wave duct contained below a deep neutral layer that prevents wave radiation. In the atmosphere, the longevity of these solutions will be affected by stratification present above a wave duct through wave radiation (Noonan and Smith 1985; Maslowe and Redekopp 1980) (Fig. 5), and improvements should focus on solutions that account for a varying stratification profile. Additionally, these solutions avoid the complication of a curved wind profile, which is commonly observed in the presence of the Great Plains NLLJ. Last, critical layers mark a level in a fluid where its speed is equal to a traveling wave. Critical layer solutions do exist for solitary waves (e.g., Maslowe and Redekopp 1980) when it is assumed that the nonlinear contributions are much larger than viscous or thermal diffusion within the layer. Future studies should focus on incorporating all the complications of the atmosphere into a more generalized nonlinear solution or family of nonlinear solutions that encapsulate all possible bore states.

A particularly frequent source of wave energy in the nonneutral layer above a wave duct is lowfrequency, deep tropospheric gravity waves generated by modulation of the latent heating/cooling profiles (Nicholls et al. 1991; Lane and Reeder 2001; AdamsSelin and Johnson 2013). As the convection matures, low-level melting and evaporative cooling rates increase (Gallus and Johnson 1991), generating gravity wave modes (i.e., $n=2,3$, where $n$ refers to twice a wave's vertical wavelength, 1 and $3 / 2$ respectively; Mapes 1993) that move more slowly than their $n=1$ counterpart away from the system with net upward motion in the lower levels of the troposphere. ${ }^{11}$ This net upward motion results in cooler, moister low levels that are more favorable to additional convective development (Mapes 1993; Fovell 2002; Fovell et al. 2006; Adams-Selin and Johnson 2010, 2013).

Microphysical low-level cooling within convection is a causal factor for both the cold pool and the low-frequency gravity waves; the strength, speed, and depth of the cold pool directly impacts bore generation. Therefore convection can generate both low-frequency gravity waves and bores at the same time. Recent studies show that tropospheric gravity waves and a bores have overlapping ranges of speeds. The bores from IHOP_2002 examined by
Haghi et al. (2017) had a median velocity of approximately $11 \mathrm{~m} \mathrm{~s}^{-1}$, with only a few peak speeds reaching over $20 \mathrm{~m} \mathrm{~s}^{-1}$. Given stratification, wave speeds corresponding to $n=2$ or $n=3$ wave modes would be approximately 15 and $10 \mathrm{~m} \mathrm{~s}^{-1}$, respectively. Thus, while bores are the result of a change in the SBL flow regime from supercritical to subcritical due to the intrusion of a convective outflow, and tropospheric gravity waves are a manifestation of the heating profile of the convection, it is likely that convection could generate tropospheric gravity waves and bores simultaneously. Moreover, both tropospheric gravity waves and bores move at similar speeds and both act to decrease static stability by lifting the lowest levels of the atmosphere. Current theory does not address how these two phenomena interact. Future numerical modeling studies should aim to isolate and understand how each phenomenon contributes to the complex patterns in the prestorm environment.

The four previously discussed improvements to theory will be a challenge to incorporate into weather prediction models. First, bores are a challenge to observe in the field because the current network of vertical profilers is sparse. Second, surface observations, while relatively abundant, can only approximate the nature of a density current or bore/ wave based on assumptions of hydrostatics. While current weather prediction models can supplement the lack of observations, the evolution of the bore in a numerical weather prediction model is very sensitive to the choice of the microphysics and boundary layer schemes. Therefore, an emphasis should be placed on evaluating the benefit of a dense network of vertical profilers that can observe atmospheric bores.

Integrating a profiling observational network. The PECAN campaign was designed to sample bores, obtaining both horizontal and vertical transects (e.g., Figs. 1, 2, and 6). While the observational platforms did indeed obtain data to meet the PECAN bore objectives, these data will also be used to direct future endeavors toward a more realized bore-conscious observing network. As of now, an appropriate network should have the capacity to characterize the SBL $\left(h_{0}\right.$ and $\Delta \theta)$, observe the speed of the leading jump $\left(C_{b}\right)$ or solitary wave $\left(C_{\mathrm{sw}}\right)$, sample the expansion of an SBL by a bore and its indirect displacement above an SBL $\left(h_{1}\right)$, sample the wind circulations and temperature profile inside the subcritical regime or soliton, and, if possible, observe the speed $C_{\mathrm{dc}}$ and depth $d_{0}$ of the

\footnotetext{
${ }^{11}$ Previous studies have found an overall net upward displacement of lower levels after passage of $n=1,2$, and 3 waves (Lane and Reeder 2001), but the interaction of multiple low-frequency gravity wave modes is an area of active research.
} 
convective outflow that generated the bore. Refer back to Fig. 4 for a depiction of these parameters.

Scanning precipitation radars, such as the National Weather Service Weather Surveillance Radar-1988 Doppler (WSR-88D) systems, are able to observe "fine lines" in the radar backscatter. These are narrow regions of enhanced clear air echoes due to convergence in the boundary layer (Russell and Wilson 1997; Haghi et al. 2017; Wilson and Roberts 2006), and can be used to estimate $C_{\mathrm{dc}}, C_{b}$, and $C_{\mathrm{sw}}$. In fact, density currents, bores, and solitons can all exhibit a train of multiple fine line clear-air echoes in radar reflectivity. The multiple fine lines are assumed to be oscillations caused by gravity waves (Wilson and Roberts 2006; Haghi et al. 2017), either along the interface of a stratified region density current or undular bore (e.g., Mueller et al. 2017), or by nature of the soliton itself. The radar echoes are generally due to insects (Wilson et al. 1994), even at night (Martin and Shapiro 2005). While there should be recognition of the undulations, speed calculations should focus on isolating the jump or density current head, because a gravity wave will have a phase speed that is not necessarily equal to the bore or density current speed (Baines 1995). Since these clear-air echoes are quite weak, a Next Generation Weather Radar (NEXRAD) and S-band
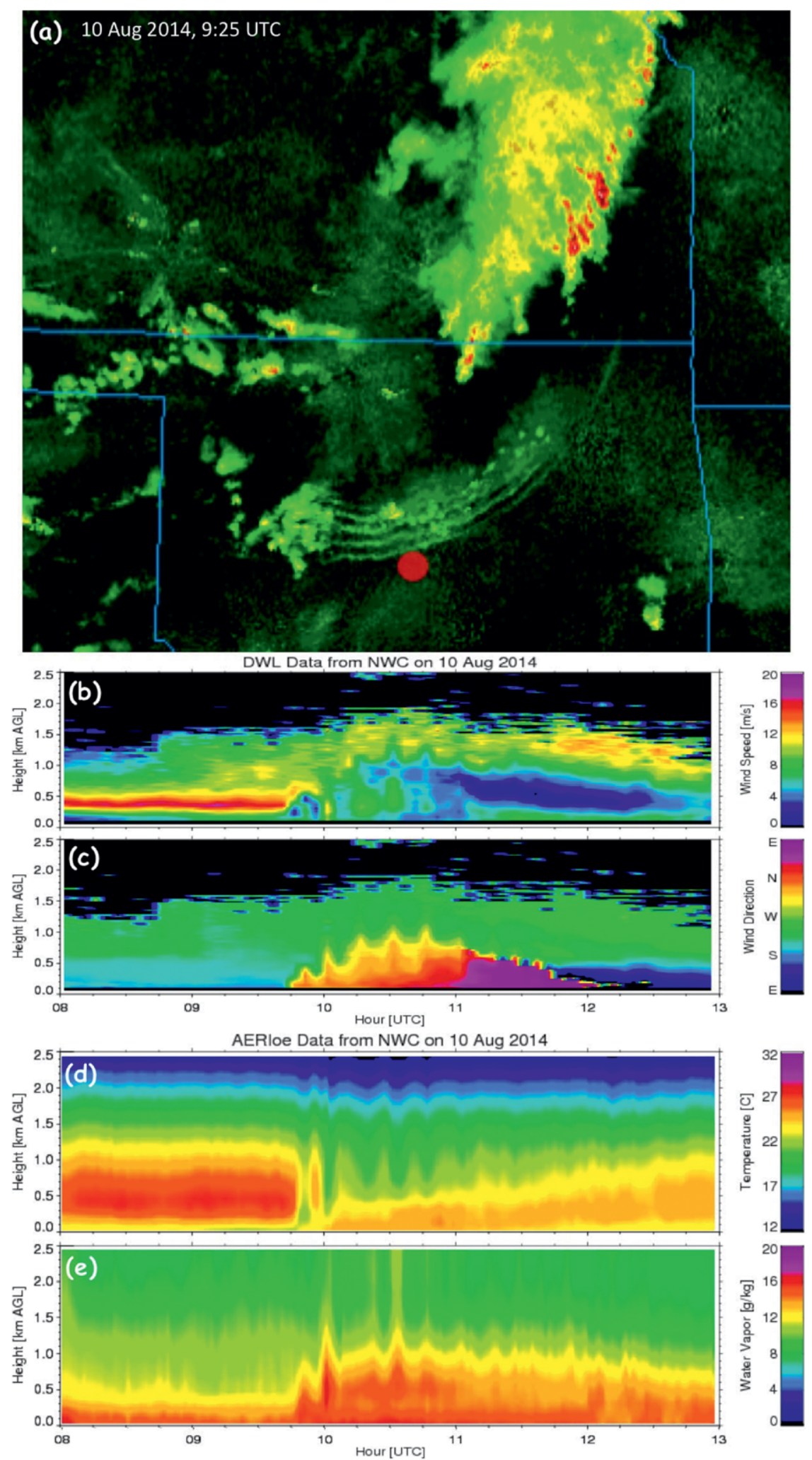

Fig. 6. Illustration of an undular bore emerging from an MCS cold pool. (a) Mosaic of WSR-88D reflectivity at 0925 UTC. The red dot shows the location of the profiling systems analyzed in the remaining panels. (b) Horizontal wind speed and (c) direction from the Doppler lidar (2-min resolution). (d) Temperature and (e) humidity retrieved from a collocated AERI (2-min resolution). The profilers were located at the National Weather Center in Norman, OK. 
dual-polarization Doppler radar (S-Pol) reflectivity composite was developed that kept weak echoes while removing anomalous signals like ground clutter (Hubbert et al. 2009). In the case that the lofted layers are humid enough, then bores may be seen also as cloud lines in satellite imagery (e.g., Goler et al. 2006).

Instruments which capture the vertical layering of the atmosphere are very useful for determining $h_{0}, h_{1}$, and $d_{0}$. Radiosondes are capable of observing $h_{0}$ but are incapable of measuring time evolution and are rarely released during the night. Instead, to capture the vertical structure of a prebore environment and the bore, a backscatter lidar detects aerosol layers, and as aerosols are very small they often serve as tracers of atmospheric motion. Thus, a backscatter lidar is able to provide measurements of $h_{0}$ and $d_{0}$ with time (Koch et al. 2008a; Mueller et al. 2017), and also the vertical displacement induced by the bore and hence $h_{1}$. However, preference should be given to Doppler lidars, which not only observe aerosol layers like a backscatter lidar but also measure the Doppler shift of the backscattered signal to obtain the horizontal and vertical motions along with turbulence using a scanning strategy that includes scanning in elevation and azimuth (e.g., Berg et al. 2017; Fulton et al. 1990). There were multiple backscatter and Doppler lidars deployed during PECAN, both on the ground in the fixed and mobile PISAs and on the aircraft.

To measure the SBL inversion strength $(\Delta \theta)$ along with thermodynamic changes due to the passage of a bore, studies show that employed atmospheric emitted radiance interferometers (AERIs; Toms et al. 2017; Mueller et al. 2017) and microwave radiometers (Knupp 2006; Coleman and Knupp 2011) are quite useful. The AERIs measure downwelling spectral infrared radiance, from which profiles of temperature and humidity are retrieved (Turner and Löhnert 2014). Similarly, thermodynamic profiles can also be retrieved from the observations made by microwave radiometers, which measure downwelling microwave radiation at multiple microwave frequencies (Solheim et al. 1998). Both of these passive remote sensors are able to provide thermodynamic profiles through the boundary layer at high temporal resolution (better than $5 \mathrm{~min}$ ). However, the vertical resolution of the profiles retrieved from these passive sensors is coarse relative to lidars (Löhnert et al. 2009; Blumberg et al. 2015). In addition to AERIs and microwave radiometers, water vapor profiles across bores have been measured using Raman lidars (Koch et al. 1991; Demoz et al. 2005) and differential absorption lidars (DIALs) (Koch et al. 2008b). Recent advances in micropulse water vapor DIALs using diode-based laser transmitters (Spuler et al. 2015) are very promising as the water vapor profiles measured by these systems have higher accuracy and resolution than passive remote sensors (Weckwerth et al. 2016; Weckwerth and Parsons 2006). However, these micropulse DIALs require aerosol particles to backscatter the outgoing laser radiation toward the receiver, and thus the signal-to-noise often drops precipitously above the residual layer due to the relative lack of aerosol particles.

These profiling systems used during PECAN have revealed aspects of bore evolution, vertical structure, and layer displacements that cannot be accommodated by hydraulic theory. For instance, in multiple cases the second wave crest was persistently higher than the first wave crest (Toms et al. 2017; Mueller et al. 2017; Grasmick et al. 2018). In many cases, wave energy appears to dissipate into turbulence behind the second wave. Observations such as these pose needed challenges to theories and models, thereby improving our ability to forecast their evolution and impacts.

PECAN observations are also useful to explore how a bore triggers new convection. As an example, the bore in Fig. 6 produced sufficient lift for CI, but the resulting deep convection was rather benign and scattered because ultimately the middle troposphere was too dry to maintain the convection. Assessing not only the moisture content of the atmosphere, but also the elevated convective available potential energy (CAPE) and convective inhibition for specific source layers within/above the SBL (e.g., Grasmick et al. 2018) requires accurate temperature and water vapor profile observations. AERIs are able to make reasonably accurate water vapor measurements in the lowest $1-2 \mathrm{~km}$ above the ground, but the information content decreases markedly above this level (Turner and Löhnert 2014). Additional observations, such as those from a water vapor lidar, can be included in the AERI retrieval to improve its information content and accuracy above $2 \mathrm{~km}$ (Turner and Blumberg 2019).

The PECAN field phase was limited to a 1.5-month period in the Great Plains. Ultimately, an operational network of continuous wind and thermodynamic profiling sensors should be explored. The U.S. National Academies proposed that an operational network of profiling systems be developed across the United States, at an initial resolution of $\sim 400 \mathrm{~km}$ (National Research Council 2009). Such a network would facilitate data assimilation (DA) efforts, allow description of the full range of bore properties and bore climatology, and yield further insight into the interaction of bores and deep convection, such as the relation between the characteristics of the ducting layer 
in the prebore environment and the magnitude of the bore lift. Traditionally, the Scorer parameter, which is used to identify ducting layers (e.g., Koch et al. 2008a), has been computed from radiosonde observations. Radiosondes have excess vertical resolution for this purpose, and typically lack time resolution. Both issues can be addressed by the combined use of remotely sensed thermodynamic (e.g., AERIs) and kinematic (e.g., Doppler lidar) data, as demonstrated in Toms et al. (2017) and illustrated in Fig. 6.

DA techniques for optimal bore resolution. The purpose of DA is to push a model state toward a more accurate depiction of the atmosphere by incorporating observational data (Houtekamer and Zhang 2016; Bannister 2017). DA advances have significantly contributed to improvements in model forecast skill (e.g., Johnson et al. 2015). Obtaining a more accurate model state requires the assimilation of varying scales. For example, large-scale observations are necessary to capture the forcing mechanisms and thermodynamic responsible for convection, while finer-scale observations are required to precisely resolve the
SBL structure that allows for the outflow to generate a bore. Forecast systems and their DA operational models have been designed neither to specifically assimilate data from profiling systems, such as those used during PECAN (varying spatial density, varying uncertainty with height, high temporal resolution) nor to resolve bores (i.e., horizontal scales $\sim 10 \mathrm{~km}$; sharp vertical gradients). Based on PECAN observations, research is ongoing to learn how to optimally assimilate these observational data. As an example, Fig. 7 juxtaposes observations with preprocessed and non-preprocessed simulations and demonstrates that preprocessing and testing can significantly improve the forecast of a long-lived MCS. This finding is in part due to the better analysis and forecast of both the convection that ultimately grows into this MCS and the boundary layer characteristics that influence the bore that helps in maintaining the MCS. The bore is depicted realistically only when the observations are meticulously preprocessed prior to being assimilated.

NWP models can better simulate a bore if the SBL, LLJ, and parent MCS (including the life cycle of the convectively induced density current) are more

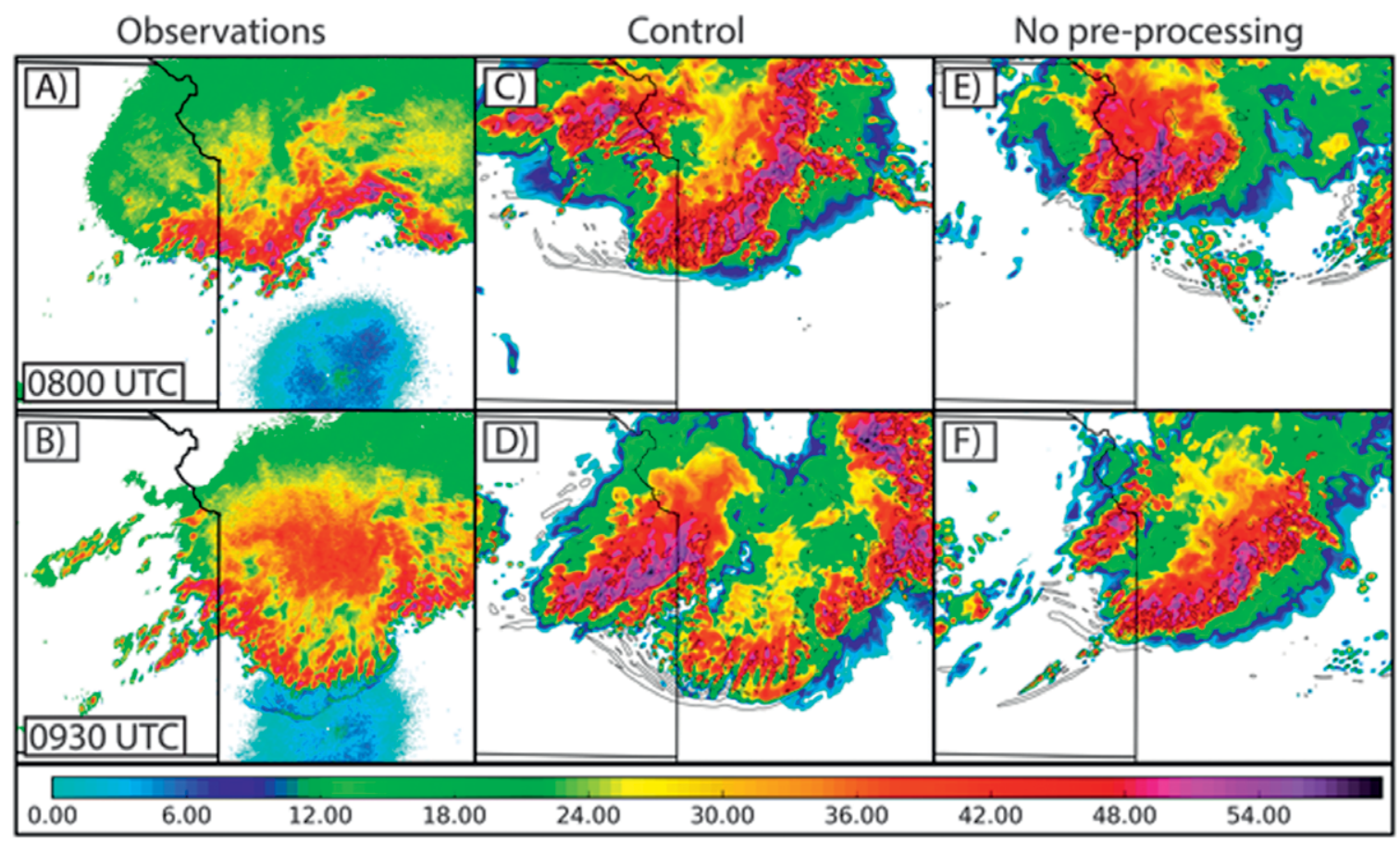

FIG. 7. (a),(b) Observed base reflectivity from KSGF and (c)-(f) simulated composite reflectivity for a mesoscale convective system in western Missouri and valid at (a),(c),(e) 0800 and (b),(d),(f) 0930 UTC 26 Jun 2015 . Also overlaid in (c)-(f) are 850-hPa vertical velocity contours of $+0.5 \mathrm{~m} \mathrm{~s}^{-1}$. Both forecasts in (c)-(f) were initialized at 0I30 UTC 26 Jun 2015 after 21 h of data assimilation on an outer I2-km domain, followed by $4.5 \mathrm{~h}$ of data assimilation on an inner 4-km domain centered over the PECAN region. Only conventional in situ and PECAN observations were assimilated on the outer domain, whereas conventional, PECAN, and radar observations (reflectivity and radial velocity) were assimilated on the inner domain. Meticulous preprocessing steps for all PECAN observations were only applied to the simulations in (c) and (d). 


\begin{tabular}{|c|c|c|}
\hline Experiment & Strength & Speed $\left(\mathrm{m} \mathrm{s}^{-1}\right)$ \\
\hline Baseline & 1.81 & 8.10 \\
\hline ALLIOP & 1.55 & 6.48 \\
\hline DENYsfc & 1.52 & 5.56 \\
\hline DENYprof & 1.46 & 4.71 \\
\hline DENYsond & 1.32 & 7.45 \\
\hline DENYaeri & 1.30 & 6.48 \\
\hline Observation & 1.42 & 5.90 \\
\hline
\end{tabular}

accurately represented. This dependence is evident in a DA experiment simulating the 11 July bore IOP. Comparisons between PECAN observations and the model simulation indicate that assimilation of different types of PECAN special observations has different positive impacts on the bore forecast, including impacts on the bore speed and amplitude (Table 1) and the overall qualitative bore structure (Fig. 8, Table 1). This DA experiment will be systematically expanded to include 10 PECAN bore cases, and to investigate the relative merits of each type of PECAN observations. A separate ongoing study focuses on assessing the impact of PECAN observations not just on bore evolution, but also on the downstream impacts of a bore on new and sustained convection (Chipilski et al. 2018b). Together, these studies will help guide the design of future observation networks in order to include adequate sampling of bores and their mesoscale environments.

There are at least two other relevant bore-related DA challenges. The first one is the lack of observations to capture the full spatial, vertical, and temporal extent of bores. While the assimilation of sparse observations may improve the analysis of bores locally, the unobserved regions may remain largely unimproved because of ensemble covariance localization. ${ }^{12}$ The resulting analysis may yield dynamical inconsistencies and therefore DA improvements may be short-lived. Also, model biases and poorly sampled random errors in an MCS, cold pool, ambient stratification, and LLJ can all lead to a suboptimal use of observations (Sobash and Stensrud 2015), which is problematic for bore analyses and forecasts.

Resolution of bores in numerical weather prediction. The OU-MAP laboratory at the University of Oklahoma generated real-time convection-permitting ensemble forecasts during the PECAN field phase to provide a baseline for determining the impact of assimilating PECAN observations on numerical weather prediction (NWP). The ensemble forecasts were configured for the specific focus on convection (Johnson and Wang 2017; Johnson et al. 2017) and provided a

\footnotetext{
${ }^{12}$ Ensemble covariance localization is an ad hoc technique, common in ensemble based DA, that artificially limits the ability of observations to correct the model at distant locations. Thus, the technique is necessitated by the finite ensemble size creating sampling errors in the ensemble correlations that contaminate the comparatively small signal that is typical of locations far from the observation location. A good reference is Kondo and Miyoshi (2016).
}

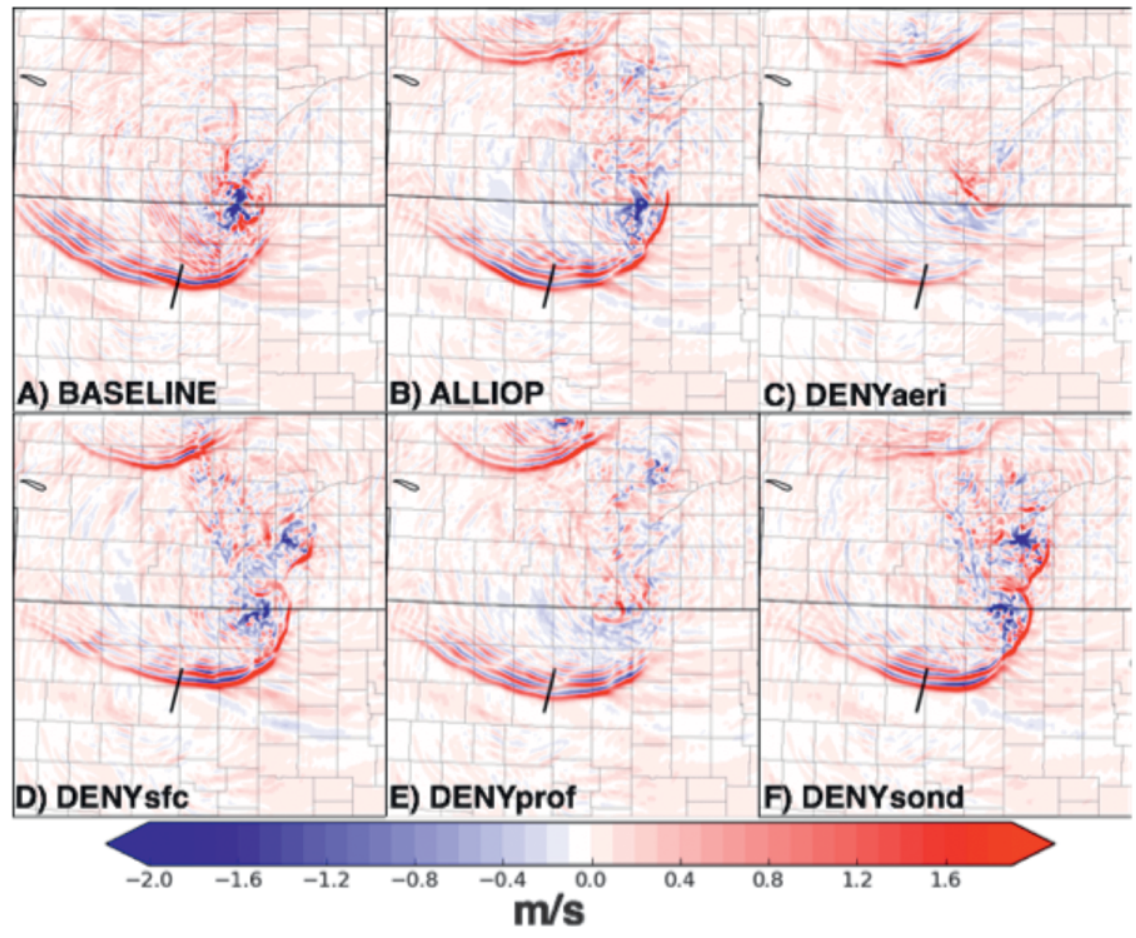

FIG. 8. Vertical velocity $\left(\mathrm{m} \mathrm{s}^{-1}\right)$ at I $\mathrm{km}$ AGL for each of the experiments described in the first section and in Table $I$. The thick black line on each panel is the cross section used to calculate the values in Table $I$. 
starting point for identifying outstanding challenges for improving the numerical simulation of bores. To date, bores have not been the focus of past efforts to design and tune NWP model grid and physics configurations. Finite horizontal and vertical resolution limits the realism of simulated bores. Ongoing WRF large-eddy simulations of multiple PECAN bore cases will help us understand the upper bounds of horizontal and vertical grid spacings that are sufficient to resolve bores and their interaction with deep convection (Johnson and Wang 2019).

Physical parameterization schemes, especially microphysics (MP) and planetary boundary layer (PBL) schemes, are utilized in models to represent subgrid-scale interactions. In regards to an atmospheric bore, the wave speed, wavelengths, and amplitude will be compromised by the inability of a scheme to properly resolve the subgrid-scale interactions. For example, most of the PBL schemes are designed to reproduce ambient stratification with no regard to the turbulence occurring in the wake of bores (Koch et al. 2008a). Studies are ongoing to better understand the relative merits of different PBL schemes for simulating bores, to examine bore processes on scales of $\sim 100 \mathrm{~m}$, and the upscale impacts of directly resolving such processes using large-eddy simulations (LES). Density current formation and movement in models are dependent upon the choice of the MP scheme, which implies that bore formation and evolution are also dependent on the MP scheme. Johnson et al. (2018) confirmed that MP schemes do indeed change the representation of bores in a 11 July PECAN IOP case study.

Coarser grids in larger-scale, longer-forecast models require a parameterization of the processes maintaining convection including cold pools, bores, and gravity waves. Accurate parameterizations of these processes in global models also require representation of the uncertainty through the use of stochastic physics (e.g., Leutbecher et al. 2017). The parameterization of bores stands at a level of complexity on top of the preexisting problem of properly parameterizing convective cold pools (generally assumed to occur within a single column of the model, e.g., Moncrieff 2010; Garcia-Carreras et al. 2013).

An objective methodology for the detection and verification of bore forecasts, both explicitly resolved and in bulk, is needed. Despite the large volume of observations collected as part of the PECAN field campaign, the construction of spatially and temporally continuous bore composites against which the quality of models can be evaluated is challenging. Observations typically sample only a small region of (a)

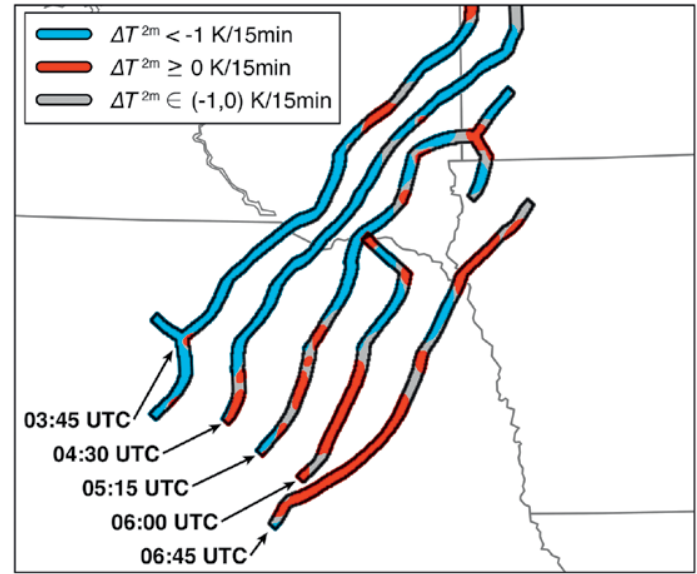

(b)

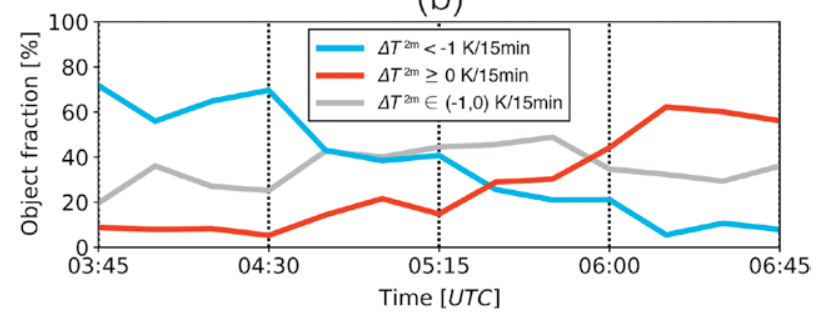

Fig. 9. Object-based algorithm for the identification and tracking of convective outflow boundaries. (a) The application of the object-based algorithm to a I-km WRF simulations over the northern Great Plains. The blue (red) color shading marks object regions where $\Delta T^{2 \mathrm{~m}}<-1 \mathrm{~K}(15 \mathrm{~min})^{-1}\left[\Delta T^{2 \mathrm{~m}} \geq 0 \mathrm{~K}(15 \mathrm{~min})^{-1}\right]$ and aims to classify the identified objects into density currents (bores). The gray color shading indicates regions where $\Delta T^{2 \mathrm{~m}} \in(-\mathrm{I}, 0) \mathrm{K}(15 \mathrm{~min})^{-1}$ and marks those parts of the identified objects that cannot be unambiguously classified into density currents or bores. (b) Display of how the fractional areal coverage of the three $\Delta T^{2 m}$ categories changes with an increasing forecast lead time. The dotted vertical lines indicate the plotting times of the convective outflow boundaries from (a).

the bore, while ground-based radars reveal little or no information about the vertical structure of the bore. The limited nature of these observations motivates the development of an object-based algorithm that can be used for bore detection and verification (Chipilski et al. 2018a).

Forecaster participation. While it is difficult to generalize the knowledge of all forecasters, one thing is clear: there exists no systematic routine to quantify the role of bores in CI. This became evident leading up to PECAN, when National Weather Service (NWS) offices located within the PECAN domain participated in the experimental design; and during PECAN when several forecasters provided forecast and nowcast guidance at the PECAN operations 
center throughout the campaign. In fact, the consensus among forecasters participating in PECAN was there exists a lack of familiarity on what exactly bores are and how can they be predicted. Therefore, it seems appropriate to offer operational forecasters training on bore dynamics, and then forecasters can inform the public of thunderstorms and possibly hazardous weather for aviation.

While education is crucial, forecast tools that can be adapted to use special soundings or model output will be tantamount in a quantitative analysis. During PECAN, operational and academic forecasters at the operations center had little confidence in their forecasts of suitable low-level stratification for gravity wave ducting, and of bore-induced CI, because the theory-based algorithm used had yet to be operationally tested. Even if the theory-based algorithm provided a perfect prognostic measure, uncertainty would still exist in the prediction of MCSs, which provide the cold pool necessary for bore formation. For example, it is well known that especially in weakly forced conditions, MCS prediction even at time scales $\ll 24 \mathrm{~h}$ is very sensitive to initial conditions and model physics choices (Weisman et al. 2015). Despite these challenges, PECAN forecasters made significant progress during the field campaign.

To make bores an integral part of the operational weather forecasts, three algorithms for have been developed using both observational and model data: a theoretical algorithm to predict the bore evolution, an object-based algorithm to identify and track developed bores in numerical models, and a heuristic algorithm that predicts the onset of bore-initiated convection. The theoretical algorithm combines hydraulic and linear wave theories to predict bore initiation and maintenance from surface observations and kinematic/thermodynamic profilers. This algorithm was used during PECAN and assisted in determining the optimal sampling strategies during bore IOPs (Geerts et al. 2017). A limitation on the theoretical algorithm was the need to manually define the properties of a density current and the accompanying ambient environment. To avoid the introduction of unnecessary biases due to forecasters' input, Chipilski et al. (2018a) developed an improved objectbased algorithm capable of objectively analyzing bores using output from convection-permitting simulations. In addition to performing a theoretical bore analysis based on hydraulic and linear wave theories, the object-based algorithm identifies and tracks explicitly resolved bores alongside resolved density currents. The object-based algorithm's ability to determine the morphology of a numerically simulated convective outflow boundary and track this boundary throughout the model forecast is depicted in Fig. 9. In particular, Fig. 9b shows that the relative frequency of points experiencing an increase in surface air temperature upon boundary passage increased from $10 \%$ to $60 \%$ during the chosen $3-\mathrm{h}$ forecasting period, suggesting that the tracked convective outflow boundary changes its morphology from a density current to a bore.

Tracking a bore in model space is an important platform on which diagnostics can be performed to predict the initiation and maintenance of boreaided elevated convection. Diagnostic variables should include bore-induced maximum lift, as well as CAPE and CIN as function of layer source height (e.g., Grasmick et al. 2018). Accordingly, the objectbased algorithm was further extended to calculate the propagation speed and strength of explicitly resolved bores. It is envisioned that a heuristic algorithm will use the object-based algorithm to approximate whether a convectively generated bore is able to lift air parcels to their LFC based on the simulated or observed bore speed and strength. Parcels that trace out a volume of air that is now freely buoyant should be suitable to indicate where CI or new convective cell growth is happening. Such model-based guidance will help forecasters anticipate pristine CI or the longevity of an MCS.

The tools outlined in this section represent an important step forward toward increasing the awareness of how bores impact convection. These tools need to be tested and refined before they can be utilized in everyday forecasting operations.

VISION OF BORE RESEARCH. The PECAN dataset is a rich resource for improved understanding of atmospheric bores and prediction of bore's evolution and interaction with deep convection. Our vision for further bore research contains the following three strategic elements.

First, research should focus on improving the aspects of convection-permitting NWP models to properly resolve key bore properties (amplitude, strength, vertical velocity). One target, which is already ongoing, is to understand how improvements such as enhanced lower tropospheric vertical resolution may improve simulation of such bore properties. Model parameterization schemes should also become the focus of bore research, as experimental simulations have shown that bore formation, structure, and evolution are highly dependent on model parameterizations, especially the PBL and microphysics schemes. For medium-to-long-range forecast models, 
which parameterize convection, parameterization schemes should be developed that function in coarseresolution model space (such as PBL height, wave duct height, and convective precipitation) as a proxy for the development of bores.

Second, an emphasis should be placed on DA studies that evaluate the impact of a Great Plains network of vertically profiling instruments and supplementary observations, as suggested by the U.S. National Academies (National Research Council 2009). During PECAN, the PECAN Integrated Sounding Array (PISA) network contained a diversity of complementary experimental remote sensors, each with its own limitations (Geerts et al. 2017). A robust DA scheme should be able to use observations from this diverse range of sensors to improve the initial conditions in the model. From the perspective of bore research, the benefits of such network could be extensive. It could provide a characterization of the full spectrum of density currents and bores, and the environments in which they evolve. A benefit of observing various bores and density currents is permitting validation of theoretical models of atmospheric bores (bore height, strength, speed, turbulence development, etc.) as a function of ambient stratification and wind shear. Moreover, an operational profiling network will allow forecasters to monitor not just the horizontal structure (radar fine lines) but also the vertical structure of a bore (bore strength, bore lifting, etc.), thus allowing them to be more informed about the potential for CI and/ or MCS maintenance (K. Haghi et al. 2018, unpublished manuscript). Looking toward the future, the multitude of bore observations from an operational network could provide a training dataset for ingenious machine learning algorithms (e.g., Gagne et al. 2017). The benefit of a machine learning algorithm is that there is no need for predefined identification variables and their corresponding global thresholds, unlike in the object-based algorithm. This would allow for the flexibility to learn the key characteristics of the mesoscale environment and cold pools that drive bore development.

Third, bore research will benefit from multidisciplinary efforts that combine a diversity of perspectives (theory, instrument development, observations, data assimilation, numerical modeling, and forecasting), as was the essence of PECAN. These kind of cross-collaborations have been successful in the meteorological field in the past. For instance, atmospheric bores were researched by scientists trained in theoretical and experimental fluid mechanics (e.g., Smith et al. 1982; Christie 1989), and the AERI, which has proven to be extremely useful for capturing the vertical structure of bores, was initially designed to improve spectral infrared radiative transfer models (Turner et al. 2016). Future improvements to theory will require observations in what is typically a highly nonlinear, unsteady environment with laminar and turbulent regions. More sensitive instruments and observational networks are needed to effectively capture bores. These tasks require the collaboration of engineers, experts in radiative transfer, data integration efforts, and observational meteorologists. Additionally, theoreticians must work closely with forecasters and research meteorologists to develop algorithms like the ones previously mentioned. This includes the development of tools in an idealized model and testing them in a forecasting setting.

This three-pronged approach will be needed to solve one of the most challenging and elusive aspects of nocturnal convection-the atmospheric bore-and to improve prediction of associated weather hazards, CI, and MCS longevity.

ACKNOWLEDGMENTS. This work is sponsored by NSF Grants AGS-1237404, AGS-1636667, and AGS1359703. We thank all of the individuals who organized and participated in the PECAN field project and the PECAN workshop. Special thanks to Coltin Grasmick for his assistance with Figs. 2 and 6, and to Amin Nehrir, Richard Ferrare, and Susan Kooi for their Fig. 1 contribution.

\section{REFERENCES}

Adams-Selin, R. D., and R. H. Johnson, 2010: Mesoscale surface pressure and temperature features associated with bow echoes. Mon. Wea. Rev., 138, 212-227, https://doi.org/10.1175/2009MWR2892.1.

— and - 2013: Examination of gravity waves associated with the 13 March 2003 bow echo. Mon. Wea. Rev., 141, 3735-3756, https://doi.org/10.1175 /MWR-D-12-00343.1.

Baines, P. G., 1995: Topographic Effects in Stratified Flows. Cambridge University Press, $482 \mathrm{pp}$.

Bannister, R. N., 2017: A review of operational methods of variational and ensemble-variational data assimilation. Quart. J. Roy. Meteor. Soc., 143, 607633, https://doi.org/10.1002/qj.2982.

Berg, L. K., R. K. Newsom, and D. D. Turner, 2017: Yearlong vertical velocity statistics derived from Doppler lidar data for the continental convective boundary layer. J. Appl. Meteor. Climatol., 56, 2441-2454, https://doi.org/10.1175/JAMC-D-16-0359.1.

Blake, B. T., D. B. Parsons, K. R. Haghi, and S. G. Castleberry, 2017: The structure, evolution, and 
dynamics of a nocturnal convective system simulated using the WRF-ARW model. Mon. Wea. Rev., 145, 3179-3201, https://doi.org/10.1175/MWR -D-16-0360.1.

Blumberg, W. G., D. D. Turner, U. Löhnert, and S. Castleberry, 2015: Ground-based temperature and humidity profiling using spectral infrared and microwave observations. Part II: Actual retrieval performance in clear-sky and cloudy conditions. $J$. Appl. Meteor. Climatol., 54, 2305-2319, https://doi .org/10.1175/JAMC-D-15-0005.1.

Browell, E. V., and Coauthors, 1997: LASE validation experiment. Advances in Atmospheric Remote Sensing with Lidar, Springer, 289-295, https://doi .org/10.1007/978-3-642-60612-0_70.

Bryan, G. H., and R. Rotunno, 2014: Gravity currents in confined channels with environmental shear. $J$. Atmos. Sci., 71, 1121-1142, https://doi.org/10.1175 /JAS-D-13-0157.1.

Carbone, R. E., J. W. Conway, N. A. Crook, and M. W. Moncrieff, 1990: The generation and propagation of a nocturnal squall line. Part I: Observations and implications for mesoscale predictability. Mon. Wea. Rev., 118, 26-49, https://doi.org/10.1175/1520 -0493(1990)118<0026:TGAPOA>2.0.CO;2.

Chipilski, H. G., X. Wang, and D. B. Parsons, 2018a: An Object-based algorithm for the identification and tracking of convective outflow boundaries in numerical models. Mon. Wea. Rev., 146, 4179-4200, https://doi.org/10.1175/MWR-D-18-0116.1.

,$- \ldots$, and,$- 2018 \mathrm{~b}$ : Impact of assimilating PECAN IOP observations on the numerical prediction of bores and bore-initiated convection. Special Symp. on Plains Elevated Convection At Night (PECAN), Austin, TX, Amer. Meteor. Soc., 841, https:// ams.confex.com/ams/98Annual/webprogram /Paper334905.html.

Christie, D. R., 1989: Long nonlinear waves in the lower atmosphere. J. Atmos. Sci., 46, 1462-1491, https:// doi.org/10.1175/1520-0469(1989)046<1462:LNWITL $>2.0 . \mathrm{CO} ; 2$.

Clark, A. J., W. A. Gallus, and T.-C. Chen, 2007: Comparison of the diurnal precipitation cycle in convection-resolving and non-convection-resolving mesoscale models. Mon. Wea. Rev., 135, 3456-3473, https://doi.org/10.1175/MWR3467.1.

Clarke, R.H., 1972: The morning glory: An atmospherichydraulic jump. J. Appl. Meteor., 11, 304-311, https://doi. org/10.1175/1520-0450(1972)011<0304:TMGAAH $>2.0 . \mathrm{CO} ; 2$.

Coleman, T. A., and K. R. Knupp, 2011: Radiometer and profiler analysis of the effects of a bore and a solitary wave on the stability of the nocturnal boundary layer. Mon. Wea. Rev., 139, 211-223, https://doi .org/10.1175/2010MWR3376.1.

Davis, C. A., K. W. Manning, R. E. Carbone, S. B. Trier, and J. D. Tuttle, 2003: Coherence of warm-season continental rainfall in numerical weather prediction models. Mon. Wea. Rev., 131, 2667-2679, https://doi .org/10.1175/1520-0493(2003)131<2667:COWCRI $>2.0 . \mathrm{CO} ; 2$

Demoz, B. B., and Coauthors, 2005: The cold front of 15 April 1994 over the central United States. Part I: Observations. Mon. Wea. Rev., 133, 1525-1543, https://doi.org/10.1175/MWR2932.1.

Feng, Z., L. R. Leung, R. A. Houze, S. Hagos, J. Hardin, Q. Yang, B. Han, and J. Fan, 2018: Structure and evolution of mesoscale convective systems: Sensitivity to cloud microphysics in convectionpermitting simulations over the United States. $J$. Adv. Model. Earth Syst., 10, 1470-1494, https://doi .org/10.1029/2018MS001305.

Fovell, R. G., 2002: Upstream influence of numerically simulated squall-line storms. Quart. J. Roy. Meteor. Soc., 128, 893-912, https://doi.org/10.1256 /0035900021643737.

_-, G. L. Mullendore, and S.-H. Kim, 2006: Discrete propagation in numerically simulated nocturnal squall lines. Mon. Wea. Rev., 134, 3735-3752, https:// doi.org/10.1175/MWR3268.1.

French, A. J., and M. D. Parker, 2010: The response of simulated nocturnal convective systems to a developing low-level jet. J. Atmos. Sci., 67, 3384-3408, https:// doi.org/10.1175/2010JAS3329.1.

Fritsch, J. M., and R. E. Carbone, 2004: Improving quantitative precipitation forecasts in the warm season: A USWRP research and development strategy. Bull. Amer. Meteor. Soc., 85, 955-965, https://doi .org/10.1175/BAMS-85-7-955.

, R. J. Kane, and C. R. Chelius, 1986: The contribution of mesoscale convective weather systems to the warm-season precipitation in the United States. J. Climate Appl. Meteor., 25, 1333-1345, https://doi .org/10.1175/1520-0450(1986)025<1333:TCOMCW $>2.0 . \mathrm{CO} ; 2$.

Fulton, R., D. S. Zrnić, and R. J. Doviak, 1990: Initiation of a solitary wave family in the demise of a nocturnal thunderstorm density current. J. Atmos. Sci., 47, 319-337, https://doi.org/10.1175/1520-0469 (1990)047<0319:IOASWF>2.0.CO;2.

Gagne, D. J., A. McGovern, S. E. Haupt, R. A. Sobash, J. K. Williams, M. Xue, and II, 2017: Storm-based probabilistic hail forecasting with machine learning applied to convection-allowing ensembles. Wea. Forecasting, 32, 1819-1840, https://doi.org/10.1175 /WAF-D-17-0010.1. 
Gallus, W. A., and R. H. Johnson, 1991: Heat and moisture budgets of an intense midlatitude squall line. $J$. Atmos. Sci., 48, 122-146, https://doi.org/10.1175/1520 -0469(1991)048<0122:HAMBOA>2.0.CO;2.

Gao, Y., L. R. Leung, C. Zhao, and S. Hagos, 2017: Sensitivity of U.S. summer precipitation to model resolution and convective parameterizations across gray zone resolutions. J. Geophys. Res. Atmos., 122, 2714-2733, https://doi.org/10.1002/2016JD025896.

Garcia-Carreras, L., and Coauthors, 2013: The impact of convective cold pool outflows on model biases in the Sahara. Geophys. Res. Lett., 40, 1647-1652, https:// doi.org/10.1002/grl.50239.

Geerts, B., and Coauthors, 2017: The 2015 Plains Elevated Convection at Night Field Project. Bull. Amer. Meteor. Soc., 98, 767-786, https://doi.org/10.1175 /BAMS-D-15-00257.1.

Goler, R., M. J. Reeder, R. K. Smith, H. Richter, S. Arnup, T. Keenan, P. May, and J. Hacker, 2006: Low-level convergence lines over northeastern Australia. Part I: The north Australian cloud line. Mon. Wea. Rev., 134, 3092-3108, https://doi.org/10.1175/MWR3239.1.

Grasmick, C., B. Geerts, D. D. Turner, Z. Wang, and T. M. Weckwerth, 2018: The relation between nocturnal MCS evolution and its outflow boundaries in the stable boundary layer: An observational study of the 15 July 2015 MCS in PECAN. Mon. Wea. Rev., 146, 3203-3226, https://doi.org/10.1175/MWR -D-18-0169.1.

Gustafson, W. I., P.-L. Ma, and B. Singh, 2014: Precipitation characteristics of CAM5 physics at mesoscale resolution during $\mathrm{MC} 3 \mathrm{E}$ and the impact of convective timescale choice. J. Adv. Model. Earth Syst., 6, 1271-1287, https://doi.org/10.1002/2014MS000334.

Haghi, K. R., D. B. Parsons, and A. Shapiro, 2017: Bores observed during IHOP_2002: The relationship of bores to the nocturnal environment. Mon. Wea. Rev., 145, 3929-3946, https://doi.org/10.1175/MWR -D-16-0415.1.

Houghton, D. D., and A. Kasahara, 1968: Nonlinear shallow fluid flow over an isolated ridge. Commun. Pure Appl. Math., 21, 1-23, https://doi.org/10.1002 /cpa.3160210103.

Houtekamer, P. L., and F. Zhang, 2016: Review of the ensemble Kalman filter for atmospheric data assimilation. Mon. Wea. Rev., 144, 4489-4532, https://doi .org/10.1175/MWR-D-15-0440.1.

Hubbert, J. C., M. Dixon, and S. M. Ellis, 2009: Weather radar ground clutter. Part II: Real-time identification and filtering. J. Atmos. Oceanic Technol., 26, 11811197, https://doi.org/10.1175/2009JTECHA1160.1.

Johnson, A., and X. Wang, 2017: Design and implementation of a GSI-based convection-allowing ensemble data assimilation and forecast system for the PECAN field experiment. Part I: Optimal configurations for nocturnal convection prediction using retrospective cases. Wea. Forecasting, 32, 289-315, https://doi.org/10.1175/WAF-D-16 -0102.1 .

$\ldots$, and —_, 2019: Multicase assessment of the impacts of horizontal and vertical grid spacing, and turbulence closure model, on subkilometer-scale simulation of atmospheric bores during PECAN. Mon. Wea. Rev., 147, 1533-1555, https://doi.org/10.1175 /MWR-D-18-0322.1.

$\longrightarrow$, _ J. R. Carley, L. J. Wicker, and C. Karstens, 2015: A comparison of multiscale GSI-based EnKF and 3DVar data assimilation using radar and conventional observations for midlatitude convectivescale precipitation forecasts. Mon. Wea. Rev., 143, 3087-3108, https://doi.org/10.1175/MWR-D-14 -00345.1 .

- - _ and S. Degelia, 2017: Design and implementation of a GSI-based convection-allowing ensemble-based data assimilation and forecast system for the PECAN Field Experiment. Part II: Overview and evaluation of a real-time system. Wea. Forecasting, 32, 1227-1251, https://doi.org/10.1175 /WAF-D-16-0201.1.

,$- \ldots$, K. Haghi, and D. Parsons, 2018: Evaluation of forecasts of a convectively generated bore using an intensively observed case study from PECAN. Mon. Wea. Rev., 146, 3097-3122, https://doi.org/10.1175 /MWR-D-18-0059.1.

Karyampudi, V. M., S. E. Koch, C. Chen, J. W. Rottman, and M. L. Kaplan, 1995: The influence of the Rocky Mountains on the 13-14 April 1986 severe weather outbreak. Part II: Evolution of a prefrontal bore and its role in triggering a squall line. Mon. Wea. Rev., 123, 1423-1446, https://doi.org/10.1175/1520 -0493(1995)123<1423:TIOTRM>2.0.CO;2.

Knupp, K., 2006: Observational analysis of a gust front to bore to solitary wave transition within an evolving nocturnal boundary layer. J. Atmos. Sci., 63, 2016-2035, https://doi.org/10.1175/JAS3731.1.

Koch, S. E., and W. L. Clark, 1999: A nonclassical cold front observed during COPS-91: Frontal structure and the process of severe storm initiation. J. Atmos. Sci., 56, 2862-2890, https://doi.org/10.1175/1520 -0469(1999)056<2862:ANCFOD>2.0.CO;2.

—, P. B. Dorian, R. Ferrare, S. H. Melfi, W. C. Skillman, and D. Whiteman, 1991: Structure of an internal bore and dissipating gravity current as revealed by Raman lidar. Mon. Wea. Rev., 119, 857-887, https://doi.org/10.1175/1520-0493(1991)119<0857: SOAIBA $>2.0 . \mathrm{CO} ; 2$. 
- W. Feltz, F. Fabry, M. Pagowski, B. Geerts, K. M. Bedka, D. O. Miller, and J. W. Wilson, 2008a: Turbulent mixing processes in atmospheric bores and solitary waves deduced from profiling systems and numerical simulation. Mon. Wea. Rev., 136, 1373-1400, https://doi.org/10.1175/2007MWR2252.1.

_ C. Flamant, J. W. Wilson, B. M. Gentry, and B. D. Jamison, 2008b: An atmospheric soliton observed with Doppler radar, differential absorption lidar, and a molecular Doppler lidar. $J$. Atmos. Oceanic Technol., 25, 1267-1287, https://doi .org/10.1175/2007JTECHA951.1.

Kondo, K., and T. Miyoshi, 2016: Impact of removing covariance localization in an ensemble Kalman filter: Experiments with 102240 members using an intermediate AGCM. Mon. Wea. Rev., 144, 4849-4865, https://doi.org/10.1175/MWR-D-15-0388.1.

Lamb, K. G., and L. Yan, 1996: The evolution of internal wave undular bores: Comparisons of a fully nonlinear numerical model with weakly nonlinear theory. J. Phys. Oceanogr., 26, 2712-2734, https://doi. org/10.1175/1520-0485(1996)026<2712:TEOIWU $>2.0 . \mathrm{CO} ; 2$.

Lane, T. P., and M. J. Reeder, 2001: Convectively generated gravity waves and their effect on the cloud environment. J. Atmos. Sci., 58, 2427-2440, https://doi .org/10.1175/1520-0469(2001)058<2427:CGGWAT $>2.0 . \mathrm{CO} ; 2$.

Leutbecher, M., and Coauthors, 2017: Stochastic representations of model uncertainties at ECMWF: State of the art and future vision. Quart. J. Roy. Meteor. Soc., 143, 2315-2339, https://doi.org/10.1002/qj .3094 .

Löhnert, U., D. D. Turner, and S. Crewell, 2009: Groundbased temperature and humidity profiling using spectral infrared and microwave observations. Part I: Simulated retrieval performance in clear-sky conditions. J. Appl. Meteor. Climatol., 48, 1017-1032, https://doi.org/10.1175/2008JAMC2060.1.

Mapes, B. E., 1993: Gregarious tropical convection. J. Atmos. Sci., 50, 2026-2037, https://doi. org/10.1175/1520-0469(1993)050<2026:GTC>2.0. $\mathrm{CO} ; 2$.

Martin, W. J., and A. Shapiro, 2005: Impact of radar tilt and ground clutter on wind measurements in clear air. J. Atmos. Oceanic Technol., 22, 649-663, https:// doi.org/10.1175/JTECH1737.1.

Maslowe, S. A., and L. G. Redekopp, 1980: Long nonlinear waves in stratified shear flows. J. Fluid Mech., 101, 321-348, https://doi.org/10.1017/S0022112080001681.

Miles, J. W., 1980: Solitary waves. Annu. Rev. Fluid Mech., 12, 11-43, https://doi.org/10.1146/annurev .fl.12.010180.000303.
Moncrieff, M. W., 2010: The multiscale organization of moist convection and the intersection of weather and climate. Climate Dynamics: Why Does Climate Vary? Geophys. Monogr., Vol. 189, Amer. Geophys. Union, 3-26, https://doi.org/10.1029/2008GM000838.

Mueller, D., B. Geerts, Z. Wang, M. Deng, and C. Grasmick, 2017: Evolution and vertical structure of an undular bore observed on 20 June 2015 during PECAN. Mon. Wea. Rev., 145, 3775-3794, https:// doi.org/10.1175/MWR-D-16-0305.1.

National Research Council, 2009: Observing Weather and Climate from the Ground Up. National Academies Press, 250 pp., https://doi.org/10.17226/12540.

Nicholls, M. E., R. A. Pielke, and W. R. Cotton, 1991: Thermally forced gravity waves in an atmosphere at rest. J. Atmos. Sci., 48, 1869-1884, https://doi .org/10.1175/1520-0469(1991)048<1869:TFGWIA $>2.0 . \mathrm{CO} ; 2$.

Noonan, J. A., and R. K. Smith, 1985: Linear and weakly nonlinear internal wave theories applied to "morning glory” waves. Geophys. Astrophys. Fluid Dyn., 33, 123143, https://doi.org/10.1080/03091928508245426.

Parker, M. D., 2008: Response of simulated squall lines to low-level cooling. J. Atmos. Sci., 65, 1323-1341, https:// doi.org/10.1175/2007JAS2507.1.

Parsons, D. B., K. R. Haghi, K. T. Halbert, B. Elmer, and J. Wang, 2018: The potential role of atmospheric bores and gravity waves in the initiation and maintenance of nocturnal convection over the southern Great Plains. J. Atmos. Sci., 76, 43-68, https://doi .org/10.1175/JAS-D-17-0172.1.

Pothecary, I. J. W., 1954: Short-period variations in surface pressure and wind. Quart. J. Roy. Meteor. Soc., 80, 395-401, https://doi.org/10.1002/qj.49708034509. Rayleigh, L., 1914: On the theory of long waves and bores. Proc. Roy. Soc. London, 90A, 324-328, https:// doi.org/10.1098/rspa.1914.0055.

Rottman, J. W., and J. E. Simpson, 1989: The formation of internal bores in the atmosphere: A laboratory model. Quart. J. Roy. Meteor. Soc., 115, 941-963, https://doi.org/10.1002/qj.49711548809.

— mosphere. J. Atmos. Sci., 50, 2116-2136, https://doi .org/10.1175/1520-0469(1993)050<2116:SWITA $>2$ $.0 . \mathrm{CO} ; 2$.

Russell, R. W., and J. W. Wilson, 1997: Radar-observed "fine lines" in the optically clear boundary layer: Reflectivity contributions from aerial plankton and its predators. Bound.-Layer Meteor., 82, 235-262, https://doi.org/10.1023/A:1000237431851.

Scorer, R. S., 1949: Theory of waves in the lee of mountains. Quart. J. Roy. Meteor. Soc., 75, 41-56, https:// doi.org/10.1002/qj.49707532308. 
Smith, R. K., G. Roff, and N. Crook, 1982: The morning glory: An extraordinary atmospheric undular bore. Quart. J. Roy. Meteor. Soc., 108, 937-956, https://doi .org/10.1002/qj.49710845813.

Sobash, R. A., and D. J. Stensrud, 2015: Assimilating surface mesonet observations with the EnKF to improve ensemble forecasts of convection initiation on 29 May 2012. Mon. Wea. Rev., 143, 3700-3725, https://doi.org/10.1175/MWR-D-14 -00126.1 .

Solheim, F., J. R. Godwin, E. R. Westwater, Y. Han, S. J. Keihm, K. Marsh, and R. Ware, 1998: Radiometric profiling of temperature, water vapor and cloud liquid water using various inversion methods. Radio Sci., 33, 393-404, https://doi.org/10.1029 /97RS03656.

Spuler, S. M., K. S. Repasky, B. Morley, D. Moen, M. Hayman, and A. R. Nehrir, 2015: Field-deployable diode-laser-based differential absorption lidar (DIAL) for profiling water vapor. Atmos. Meas. Tech., 8, 1073-1087, https://doi.org/10.5194/amt -8-1073-2015.

Stastna, M., and K. G. Lamb, 2002: Large fully nonlinear internal solitary waves: The effect of background current. Phys. Fluids, 14, 2987-2999, https://doi .org/10.1063/1.1496510.

Tepper, M., 1950: A proposed mechanism of squall lines: The pressure jump line. J. Meteor., 7, 21-29, https:// doi.org/10.1175/1520-0469(1950)007<0021:APMOSL $>2.0 . \mathrm{CO} ; 2$.

Toms, B. A., J. M. Tomaszewski, D. D. Turner, and S. E. Koch, 2017: Analysis of a lower tropospheric gravity wave train using direct and remote sensing measurement systems. Mon. Wea. Rev., 145, 2791-2812, https://doi.org/10.1175/MWR-D-16-0216.1.

Trier, S. B., C. A. Davis, and D. A. Ahijevych, 2010: Environmental controls on the simulated diurnal cycle of warm-season precipitation in the continental United States. J. Atmos. Sci., 67, 1066-1090, https:// doi.org/10.1175/2009JAS3247.1.

Turner, D. D., and U. Löhnert, 2014: Information content and uncertainties in thermodynamic profiles and liquid cloud properties retrieved from the groundbased Atmospheric Emitted Radiance Interferom- eter (AERI). J. Appl. Meteor. Climatol., 53, 752-771, https://doi.org/10.1175/JAMC-D-13-0126.1.

—, and W. G. Blumberg, 2019: Improvements to the AERIoe thermodynamic retrieval profile algorithm. IEEE J. Sel. Top. Appl. Earth Obs. Remote Sens., 12, 1339-1354, https://doi.org/10.1109 /JSTARS.2018.2874968.

— E. E. Mlawer, and H. E. Revercomb, 2016: Water vapor observations in the ARM Program. The Atmospheric Radiation Measurement (ARM) Program: The First 20 Years, Meteor. Monogr., No. 57, Amer. Meteor. Soc., https://doi.org/10.1175 /AMSMONOGRAPHS-D-15-0025.1.

Weckwerth, T. M., and D. B. Parsons, 2006: A review of convection initiation and motivation for IHOP_2002. Mon. Wea. Rev., 134, 5-22, https://doi.org/10.1175 /MWR3067.1.

—, K. J. Weber, D. D. Turner, and S. M. Spuler, 2016: Validation of a water vapor micropulse differential absorption lidar (DIAL). J. Atmos. Oceanic Technol., 33, 2353-2372, https://doi.org/10.1175/JTECH -D-16-0119.1.

Weisman, M. L., and Coauthors, 2015: The Mesoscale Predictability Experiment (MPEX). Bull. Amer. Meteor. Soc., 96, 2127-2149, https://doi.org/10.1175 /BAMS-D-13-00281.1.

White, B. L., and K. R. Helfrich, 2012: A general description of a gravity current front propagating in a twolayer stratified fluid. J. Fluid Mech., 711, 545-575, https://doi.org/10.1017/jfm.2012.409.

$\longrightarrow$, and _ 2014: A model for internal bores in continuous stratification. J. Fluid Mech., 761, 282-304, https://doi.org/10.1017/jfm.2014.599.

Wilson, J. W., and R. D. Roberts, 2006: Summary of convective storm initiation and evolution during IHOP: Observational and modeling perspective. Mon. Wea. Rev., 134, 23-47, https://doi.org/10.1175 /MWR3069.1.

—, T. M. Weckwerth, J. Vivekanandan, R. M. Wakimoto, and R. W. Russell, 1994: Boundary layer clear-air radar echoes: Origin of echoes and accuracy of derived winds. J. Atmos. Oceanic Technol., 11, 1184-1206, https://doi.org/10.1175/1520 -0426(1994)011<1184:BLCARE>2.0.CO;2. 


\section{AMS BOOKS RESEARCH APPLICATIONS HISTORY}

CLIMATE

The Thinking Person's Guide to Climate Change ROBERT HENSON

This fully updated and expanded revision of The Rough Guide to Climate Change combines years of data with recent research. It is the most comprehensive acknowledging controversies but standing strong in its stance that the climate is changing-and something needs to be done.

(c) 2014, PAPERBACK, 520 PAGES,

ISBN: 978-1-935704-73-7

LIST \$30 MEMBER \$20 overview of climate science,

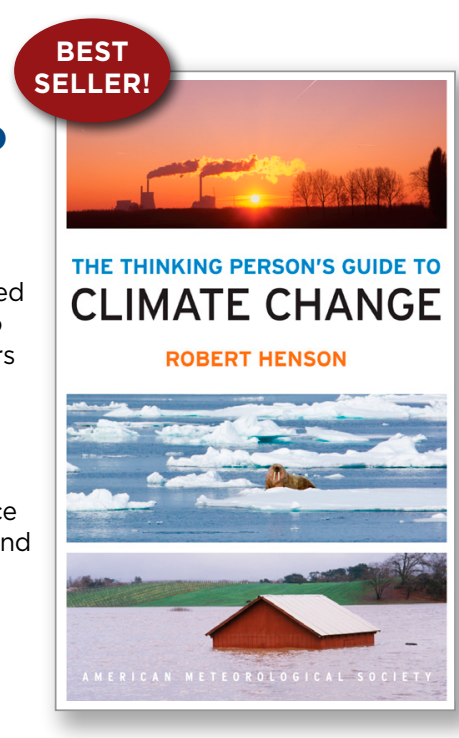

\section{Climate Conundrums:} What the Climate Debate Reveals about Us

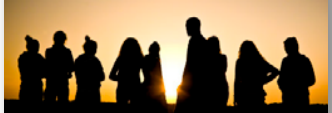

WILLIAM B. GAIL

This is a journey through how we think individually and collectively, about humanity's relationship with nature, and more. Can we make nature better? Could science and religion reconcile? Gail's insights on such issues help us better understand who we are and find a way forward.

(c) 2014, PAPERBACK, 240 PAGES, ISBN: 978-1-935704-74-4 LIST \$30 MEMBER \$20
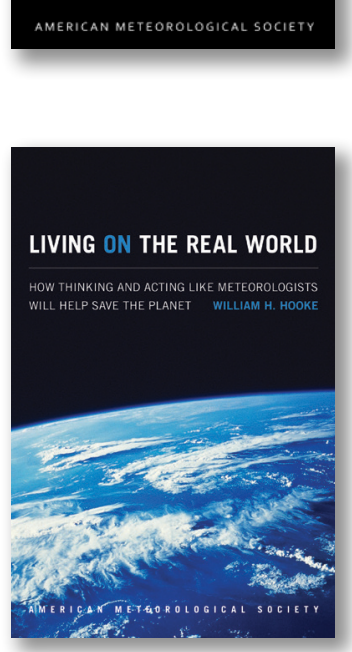

\section{Living on the}

\section{Real World:}

How Thinking and Acting Like Meteorologists

Will Help Save the Planet WILLIAM H. HOOKE

Meteorologists focus on small bits of information while using frequent collaboration to make decisions. With climate change a reality, William $\mathrm{H}$. Hooke suggests we look to the way meteorologists operate as a model for how we can solve the 21st century's most urgent environmental problems.

(c) 2014, PAPERBACK, 272 PAGES, ISBN 978-1-935704-56-0 LIST \$30 MEMBER \$22

\section{Synoptic-Dynamic Meteorology Lab Manual:}

Visual Exercises to Complement Midlatitude Synoptic Meteorology

\section{GARY LACKMANN, BRIAN E. MAPES, AND KEVIN R. TYLE}

These labs link theoretical concepts with groundbreaking visualization to elucidate concepts taught in the award-winning companion textbook by Gary Lackmann, Midlatitude Synoptic Meteorology.

(c) 2017, PAPERBACK, 126 PAGES, ISBN 978-1-878220-26-4 LIST \$80 MEMBER \$60 STUDENT \$50

\section{GUIDES}

\section{An Observer's Guide to Clouds}

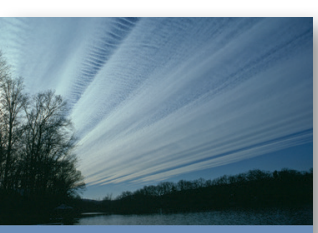

AN OBSERVER'S GUIDE CLOUDS AND WEATHER A NORTHEASTERN PRIMER ON PREDICTION

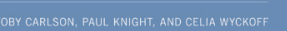
and Weather:

A Northeastern Primer on Prediction

TOBY CARLSON, PAUL KNIGHT, AND CELIA WYCKOFF

With help from Penn State experts, start at the beginning and go deep. This primer, intended for both serious enthusiasts and new meteorology students, will leave you with both refined observation skills and an understanding of the complex science behind the weather: the ingredients for making reliable predictions of your own. It connects fundamental meteorological concepts with the processes that shape

weather patterns, and will make an expert of any dedicated reader.

(c) 2014, PAPERBACK, 210 PAGES,

ISBN: 978-1-935704-58-4 LIST \$30 MEMBER \$20

\section{Eloquent Science:}

A Practical Guide to Becoming a Better Writer, Speaker, and Atmospheric Scientist DAVID M. SCHULTZ

The ultimate communications manual for undergraduate and graduate students as well as researchers in the atmospheric sciences and their intersecting disciplines.

(c) 2009, PAPERBACK, 440 PAGES, ISBN 978-1-878220-91-2

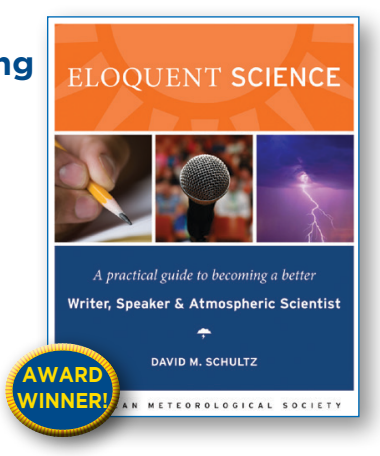

LIST \$45 MEMBER \$30 


\section{SHIPPING + DISCOUNTS AT BOOKSTORE.AMETSOC.ORG}

NEW

Verner Suomi: The Life and Work of the Founder of Satellite Meteorology

JOHN M. LEWIS WITH JEAN M. PHILLIPS, W. PAUL MENZEL, THOMAS H. VONDER HAAR, HANS MOOSMÜLLER, FREDERICK B. HOUSE, AND MATTHEW G. FEARON

Born in a Minnesotan mining town, Suomi would spend his best years next door in Wisconsin, but not before seeing the whole world-from space, that is. This is the story of the scientist, inventor, and teacher who founded satellite meteorology, written by

members of the communities that grew up around his groundbreaking work.

LIST \$3O MEMBER \$20

(c) 2016, PAPERBACK, 240 PAGES, ISBN: 978-1-944970-22-2

\section{Weather in the Courtroom: Memoirs from a Career iForensic Meteorology}
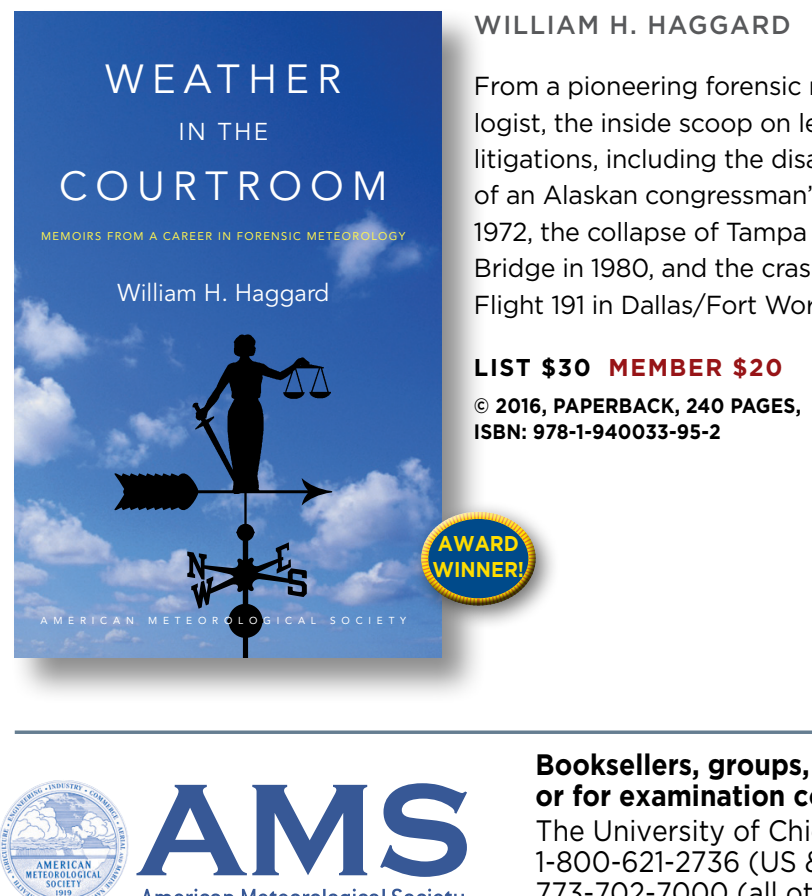

American Meteorological Society

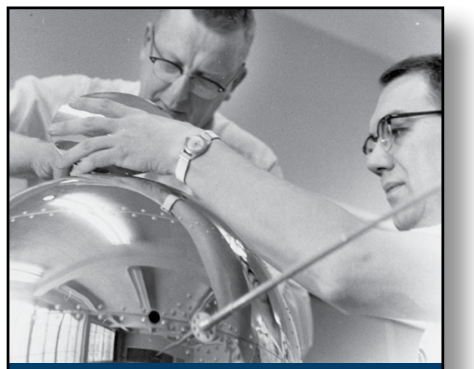

\section{Verner Suomi}

The Life and Work of the Founder of Satellite Meteorology

John M. Lewis with Jean M. Phillips,
Saul Menzel, Thomas H. Vonder Haar. Hans Moosmill Frederick B. House, and Mather, Hans Moosm

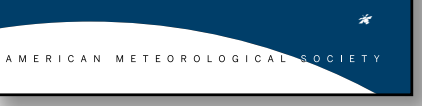

HISTORY

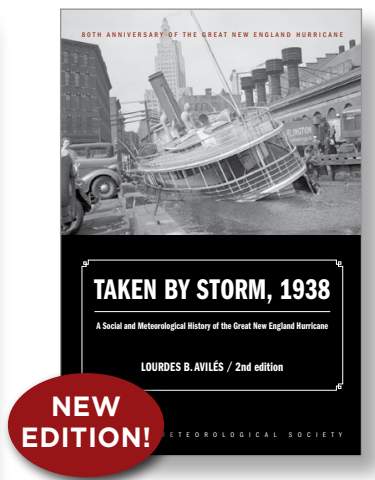

Taken by Storm, 1938:

A Social and Meteorological History of the Great New England Hurricane, 2nd Ed. LOURDES B. AVILÉS

The science behind 80TH
ANNIVERSARY OF STORM the 1938 Hurricane, which hit New England unannounced, is presented here for the first time along with new data that

sheds light on the motivations of the Weather Bureau forecasters. This compelling history successfully weaves science, historical accounts, and social analyses to create a comprehensive picture of the most powerful and devastating hurricane to hit New England to date.

(c) 2018, PAPERBACK, 288 PAGES, ISBN: 978-1-944970-24-6 LIST \$30 MEMBER \$20

\section{A Scientific Peak:}

How Boulder Became a World Center for Space and Atmospheric Science

JOSEPH P. BASSI

How did big science come to Boulder, Colorado? Joe Bassi introduces us to the characters, including Harvard sun-Earth researcher Walter Orr Roberts, and the unexpected brew of politics, passion, and sheer luck that during the Cold War era transformed this "Scientific Siberia" to home of NCAR and NOAA.

(C) 2015, PAPERBACK, 264 PAGES, ISBN: 978-1-935704-85-0 LIST PRICE: $\$ 35.00$ MEMBER PRICE: $\$ 25.00$

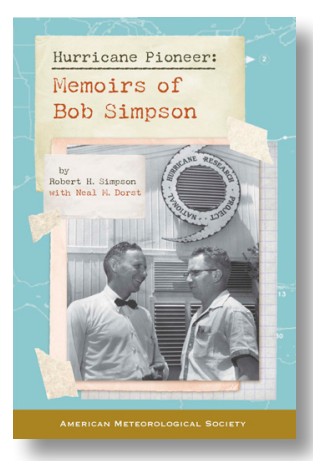
Hurricane Pioneer: Memoirs of Bob Simpson ROBERT H. SIMPSON AND NEAL DORST

In 1951, Bob Simpson rode a plane into a hurricane-just one of the many pioneering exploits you'll find in these memoirs. Bob and his wife Joanne are meteorological icons: Bob was the first director of the National Hurricane Research Project and a director of the National Hurricane Center. He helped to create the Saffir-Simpson Hurricane Scale; the public knows well his Categories 1-5. Proceeds from this book help support the AMS's K. Vic Ooyama Scholarship Fund.

(C) 2015, PAPERBACK, 156 PAGES

ISBN: 978-1-935704-75-1 LIST \$25 MEMBER \$20 
